\title{
Local Stress Field Approach for Shear Failure Assessment of Reinforced Concrete Members
}

\author{
Bahman Ghiassi ${ }^{1}$ and Masoud Soltani ${ }^{2}$
}

Received 14 December 2009, accepted 24 May 2010

\begin{abstract}
Despite extensive research on behavior of reinforced concrete in shear, there is still considerable disagreement among researchers in proposing and using a rational way of calculating the shear strength of reinforced concrete members. Due to lack of a universally accepted model for shear, shear design provisions still generally consist of empirical relationships that differ from code-to-code. In this study, a simple rational formula for calculating the shear strength of reinforced concrete elements is proposed by conducting a systematic parametric study on the response of RC elements in shear. This is done by using a computational model which simulates the post cracking behavior of RC membrane element on the basis of local stress transferring mechanism between adjacent cracks and microscopic stress transfer across cracks. Through a comparison with extensive available experimental tests conducted on RC elements, it is shown that the proposed rational relation can appropriately predict the shear strength of reinforced concrete elements under different in-plane stress conditions. Then the proposed relation is extended to the shear design of RC members and again it is shown that the predicted shear strengths are in good agreement with the experimental test results under different combination of axial, bending and shear forces.
\end{abstract}

\section{Introduction}

Although extensive research has been conducted on the behavior of reinforced concrete elements, there is still considerable disagreement among researchers in proposing and using a rational way of calculating the shear strength of reinforced concrete for different loading conditions and material properties. This is because of different influencing phenomena and parameters which extensively control the overall response of reinforced concrete members in shear and make it complex to be predicted. Most of the current design procedures for reinforced concrete elements in shear are based on the truss analogy yet, which was developed by Ritter and Moersch.

Many years ago Ritter proposed a 45 degree truss model for computing the shear strength of reinforced concrete members and became the basis of many design codes around the world (Rahal and Collins 1999). Ritter assumed that after cracking of concrete, the behavior of a reinforced concrete member is likely to that of a truss with a top longitudinal concrete chord, a bottom longitudinal steel chord, vertical steel ties, and diagonal concrete struts inclined at 45 degrees and further it was assumed that the diagonally cracked concrete cannot resist tension and the shear force is resisted by transverse steel,

\footnotetext{
${ }^{1}$ M.sc. of Earthquake Engineering, Tarbiat Modares University, Jalaale-al Ahmad Ave., Tehran, Iran.

${ }^{2}$ Associate professor, Department of Civil Engineering, Tarbiat Modares University, Jalaale-al Ahmad Ave., Tehran, Iran.

E-mail:msoltani@modares.ac.ir
}

commonly referred to as the steel contribution $\left(V_{s}\right)$.

Since then, extensive research has been conducted with the aim of improving the design methods for shear and behavior of concrete members. These studies resulted in several modifications to improve the Ritter's model like the addition of a semi-empirical concrete contribution term $\left(V_{c}\right)$ to the steel one $\left(V_{s}\right)$. Also the researches have shown that the angle of inclination of the compressive strut is not always 45 degree. Along with the experimental researches, analytical models have been developed to account for this problem. The development of the compression field theory (CFT), for torsion (Mitchell and Collins 1974), and then for shear (Collins 1978), made the calculation of the angle of inclination of the compressive strut possible but still ignored tensile stresses in the concrete. This model uses the strain conditions in the web to determine the inclination of the diagonal compressive stresses. The development of this method was a significant step toward the shear design of RC members and has appeared in CSA A23.3 (1984) Standard.

After that, extensive experimental research by Vecchio and Collins (1982) resulted in modified compression field theory (MCFT) with improvements to the CFT method, in which the tensile stresses in concrete was considered in the computations. The main assumptions made in MCFT method are as follows: 1-The principle strain directions are coincident with the principle stress direction; 2-Reinforcing bars are uniformly distributed over the element. Also, the average stresses and strains are used in the computations. This analytical method can accurately predict the behavior and shear strength of RC members in most cases and some modifications are made in the constitutive models in recent 
years to improve its disadvantages. The MCFT method shows good results in comparison to the experimental results in both predicting the behavior and shear strength in most cases. Because of the complexity of this method for design procedures, it has been simplified to be more applicable (Bentz et al. 2006), but it resulted in a decrease in the accuracy of predictions.

In this study the shear behavior of RC panels is studied based on a computational method proposed by Soltani et al. (2003) for formulating the post cracking response of reinforced concrete membrane elements in terms of stresses at the crack surfaces and taking into account all characteristics of stress transferring in RC elements. Based on this computational method, a parametric study is conducted on the response of RC elements under different conditions of material properties, reinforcement ratio and loadings which resulted in two simple and precise relations for computing the shear strength of RC elements reinforced with deformed bars and welded wire mesh.

The exactness of the proposed relation in predicting the shear strength of the RC elements is shown by comparing the results with extensive available experimental results. Then the proposed relation is extended for design of RC members under the combination of axial force, bending moment and shear and it is shown that the predicted shear strengths are appropriately accurate and also applicable to any special conditions such as large member size (size effect) or high strength concrete.

\section{Local stress field approach}

The computational method used in this research, is a method that attempts to formulate the post cracking response of reinforced concrete membrane elements in terms of stresses at the crack face, taking into account all characteristics of stress transferring in RC elements (Fig. 1). This so called "Local Stress Field Approach" was proposed by Soltani et al. (2003, 2005). The local stress-strain characteristics of concrete and reinforcing bars embedded in concrete, used in this work, are based on the extensive research activities that have been undertaken at the University of Tokyo during the past decades to investigate the fundamental mechanism of local stress transfer in RC domain (Maekawa et al. 2003). Using this method, the spatial average behavior of both concrete and reinforcing bars during the crack propagation and stabilizing of cracks can be investigated.

This method comprises different stress transfer mechanisms and phenomena such as local stress transfer along reinforcing bars, shear and dilatancy stresses transfer through aggregate interlock on the crack planes, bridging stress transfer across rough crack, dowel action and kinking of the reinforcing bars at the crack location, stress transfer of concrete parallel to the cracks, softened compression of concrete due to coexisting transverse tensile deformation and compressive damage localization between cracks (Fig. 1). So on the basis of this local analysis approach the influences of reinforcement ratio and arrangement, crack inclination and material properties on the post cracking response of concrete and reinforcement can be investigated numerically (Soltani et al. 2005).

\subsection{Local stress analysis of RC membrane ele- ments}

Figure 2(a) shows the state of stresses of a reinforced concrete element subjected to general in-plane stresses. The RC element is orthogonally reinforced with longitudinal and transverse bars placed in $x$ and $y$ direction. The principle directions of applied stresses are also shown in Fig. 2(b). The crack direction is initially considered normal to principle tensile stress at an angle $\theta$ with respect to $x$ direction. After cracking the local stress and strain states in RC element change. At a distinct cracked section, the local force normal to crack is carried by the reinforcing bars $\left(f_{c r x}, f_{c r y}\right)$ and bridging stress of the cracked concrete $\left(\sigma_{b r}\right)$. The local forces across the crack is carried by aggregate interlock $\left(\tau_{\text {agg }}\right)$ and dowel action of reinforcing bars $\left(f_{d x}, f_{d y}\right)$. Due to interlocking of aggregates at the crack plane, the compression stress due to dilatancy $\left(\sigma_{d}\right)$, is applied normal to the crack surface (Fig. 3(a)). The local force of reinforcing bars at the crack surface is partially transferred to the concrete between adjacent cracks through bond stress and anchorage effect of longitudinal and transverse bars, while the bridging stress, aggregate interlock stress, and stresses due to dowel action at crack location are directly applied to the fracturing planes.

Using the equilibrium equations, the applied stress components can be expressed based on the local stresses of cracked concrete and those of reinforcing bars. The local stresses, shown in Fig. 3, are statically equivalent with the applied stresses so:

$$
\begin{aligned}
\sigma_{x}= & \left(\sigma_{d}+\sigma_{b r}\right) \sin ^{2} \theta+\sigma_{2} \cos ^{2} \theta \\
& -2 \tau_{a g g} \sin \theta \cos \theta+\rho_{x} f_{c x}+\rho_{y} f_{d y} \\
\sigma_{y}= & \left(\sigma_{d}+\sigma_{b r}\right) \cos ^{2} \theta+\sigma_{2} \sin ^{2} \theta \\
& +2 \tau_{a g g} \sin \theta \cos \theta+\rho_{y} f_{c r y}+\rho_{x} f_{d x} \\
\tau_{x y}= & \left(\sigma_{d}+\sigma_{b r}-\sigma_{2}\right) \sin \theta \cos \theta \\
& -\tau_{a g g}\left(\cos ^{2} \theta-\sin ^{2} \theta\right)
\end{aligned}
$$

where $\sigma_{x}, \sigma_{y}$ are space-average normal stress acting on the whole domain of $\mathrm{RC}$ element in $\mathrm{x}$ and $\mathrm{y}$ direction respectively, $\sigma_{2}$ is the principle compressive stress (Fig. 2), $\rho_{x}, \rho_{y}$ are the reinforcement ratios in $\mathrm{x}$ and $\mathrm{y}$ directions respectively, and $\tau_{x y}$ is the applied shear stress in $\mathrm{x}-\mathrm{y}$ direction.

By satisfying the equilibrium and compatibility conditions at a crack plane as well as un-cracked concrete, the local stress and crack deformation can be obtained. Prior to cracking, concrete is modeled as an elastoplastic and fracture continuum by using biaxial EPF model (Okamura and Maekawa 1991). The first crack is introduced in the direction of principle tensile stress 


\section{RC Element}

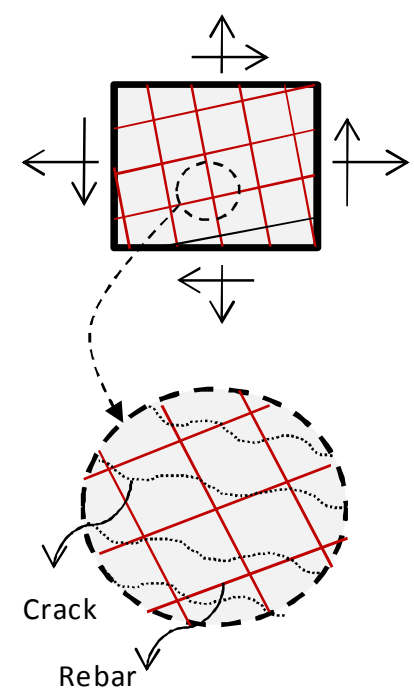

State of stresses between cracks

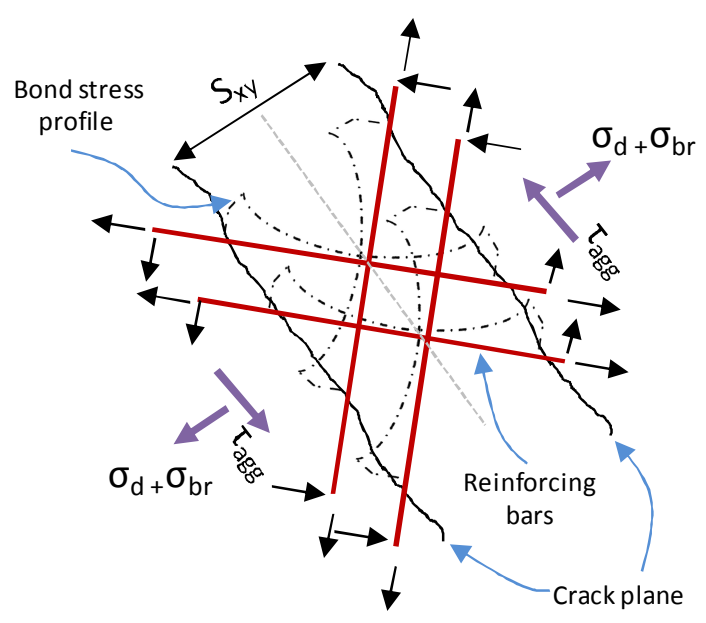

Local response

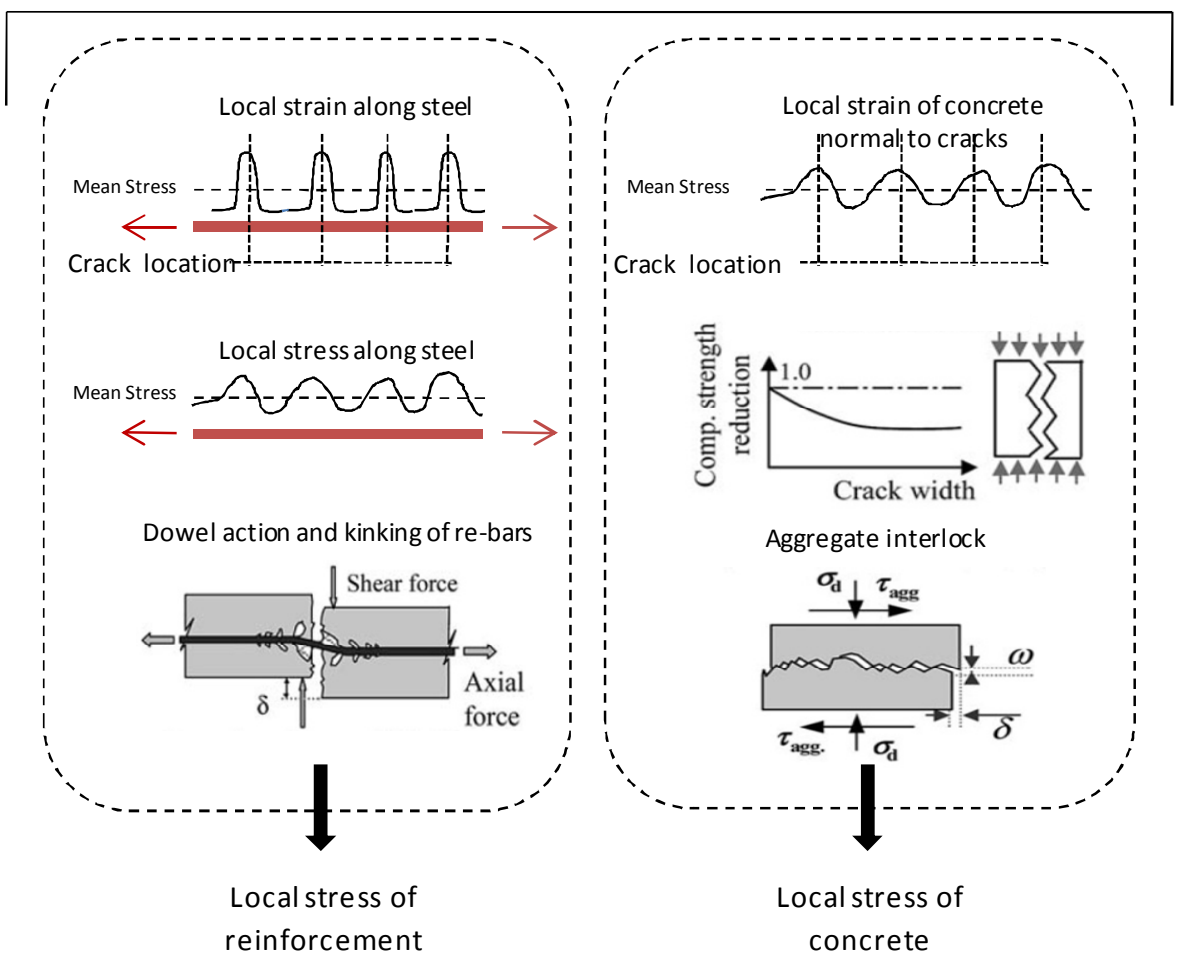

Fig. 1 Local stress transfer mechanism in RC membrane elements.

when its value reaches the cracking stress. After cracking, the implicit iterative solution is conducted in terms of local deformation of crack i.e average opening $(\omega)$ and sliding of crack planes $(\delta)$ and also axial strain in local " 2 " direction $\left(\varepsilon_{2}\right)$ as primary un-known parameters.

The computational scheme and general description of the method has been explained in (Soltani et al. 2003, 2005) and can be summarized as follows.

(a) The axial and shear deformations of steel bars are obtained by considering the local deformation in the vicinity of cracks. Using the governing equations of stress transfer along the steel bar, the profile of strains and stresses along the reinforcing bar and its local stress at the crack surface can be computed for any given steel strains by using the appropriate bond model. In this analysis the bondslip-strain model proposed by Shima et al. (1987), which is applicable for both elastic and inelastic ranges, is adopted. Also the shear force carried by reinforcing bars, dowel action, is explicitly calcu- 


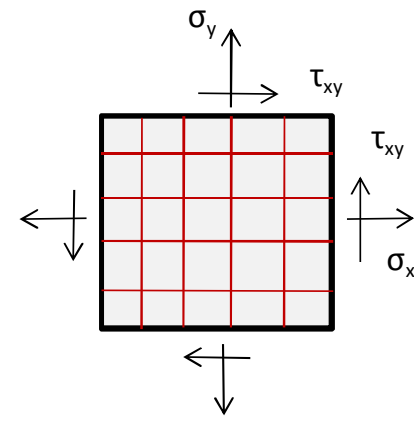

(a)

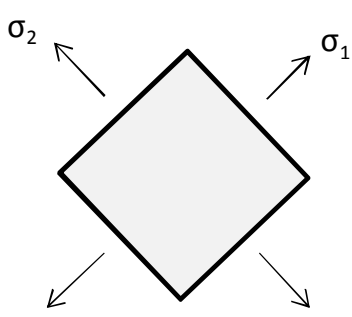

(b)
Fig. 2 RC element under in-plane stresses: (a) applied stresses; (b) principle stresses.

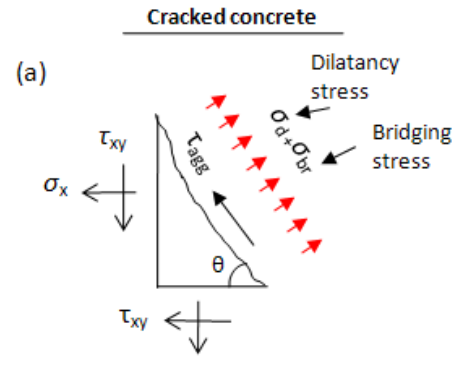

(b)

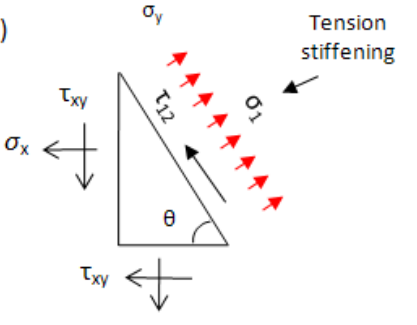

$\sigma_{\mathrm{y}}$

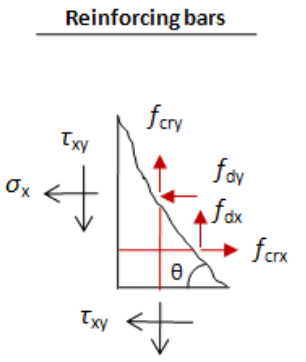

$\sigma_{\mathrm{y}}$

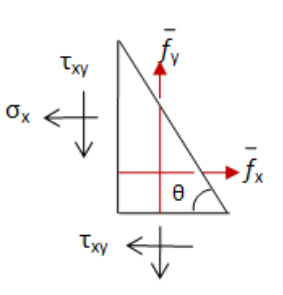

$\sigma_{y}$
Fig. 3 Stress state of cracked concrete and reinforcing bars: (a) local stresses; (b) average stresses.

lated by considering the local curvature developed in reinforcing bar in the vicinity of crack.

(b) The local stress conditions at crack planes are computed by the amount of local deformation of crack planes using the appropriate material models (Soltani et al. 2005). The average tensile stress of concrete between adjacent cracks (tension stiffening) is obtained from the local steel stresses transferred to the concrete body. The possibility of a newly formed crack is checked with the maximum local concrete stress in un-cracked concrete region. When the maximum tensile stress in concrete reaches cracking stress, a new crack is introduced in the RC domain and computation is carried out with the updated crack spacing.

(c) The average strain of RC element in global coordinate is obtained by transformation of average concrete strains on the local coordinate along a crack. The concrete and steel stresses computed in the above mentioned steps should be in equilibrium with the applied stresses defined on the global coordinates (Eqs. 1-3). Then, for any given applied stresses, the unknown average strains can be determined in an iterative way.

A comprehensive verification of this model with experimental work has been conducted for $\mathrm{RC}$ elements with deformed bars or welded wire mesh in (Soltani et al. 2003, 2004). Here, the accuracy of this analytical method in prediction of response of some reinforced concrete panels subjected to in-plane forces is reexamined. The first group of selected panels, made of deformed bars, have been tested at the University of Houston by Pang and Hsu (1995) (panels A2,A3), and the second group are the panels, made of welded wire mesh, which have been tested at the University of Toronto by Vecchio and Collins (1982) (panels PV3,PV11). The specimens' properties and loading conditions are listed in Table 1. The comparison between the experimental and analytical results is shown in Fig. 4 which confirms the reliability of the numerical method.

\subsection{Steel and concrete contribution to overall response of RC elements}

The grasp of individual contributions of differing stress transfer mechanisms and their influence to the structural response is the key for development of a rational model for failure assessment of RC elements. Herein, the discussion is directed to the individual influence of these mechanisms on the behavior and failure capacity of RC membrane elements.

As in the proposed method, all the mobilized stress components in the $\mathrm{RC}$ domain can be tracked in terms of local stress-strain characteristics and local response of the components, the average stress-strain relationship of reinforcing bars and cracked concrete can be obtained. Also, the contribution of each component i.e. the reinforcing bars and concrete to the overall behavior of the $\mathrm{RC}$ elements can be investigated which is the basis of the current study in formulizing and computing the shear strength of reinforced concrete members.

As an example the individual contribution of cracked concrete and steel bars to the overall response of RC panel PV11 was computed in terms of both average stress and local stress at the crack plane and shown in Fig. 5.

Also, the contribution of each component to the shear response of the panel can be computed, writing the equilibrium equation in y direction, which helps us to investigate the effect of transverse reinforcement and cracked concrete in the overall response and derivation of the design relationships. For the case of RC element reinforced with orthogonal reinforcing bars in direction of applied stresses, the equilibrium equation of local stress state at the crack location in y direction can be expressed as (Fig. 3):

$\tau_{x y}=\left(\sigma_{d}+\sigma_{b r}\right) \cot \theta+\tau_{a g g .}+\rho_{y} f_{c r y}+\rho_{x} f_{d x}-\sigma_{y} \cot \theta$ 
Table 1 Specimen details and loading condition.

\begin{tabular}{|c|c|c|c|c|c|c|c|c|c|c|c|}
\hline \multirow[b]{2}{*}{ Panel } & \multicolumn{2}{|c|}{ Concrete } & \multicolumn{8}{|c|}{ Reinforcing Bars } & \multirow{2}{*}{$\begin{array}{l}\text { Loading } \\
\tau_{x y}: \sigma_{x}: \sigma_{y}\end{array}$} \\
\hline & $\begin{array}{c}f^{\prime} c \\
(\mathrm{MPa})\end{array}$ & $\varepsilon_{c} \times 10^{-3}$ & $\begin{array}{l}\rho_{x} \\
(\%)\end{array}$ & $\begin{array}{c}f_{y x} \\
(\mathrm{MPa})\end{array}$ & $\begin{array}{c}d_{b x} \\
(\mathrm{~mm})\end{array}$ & $\begin{array}{c}L_{x} \\
(\mathrm{~mm})\end{array}$ & $\begin{array}{l}\rho_{y} \\
(\%)\end{array}$ & $\begin{array}{c}f_{y y} \\
(\mathrm{MPa})\end{array}$ & $\begin{array}{c}d_{b y} \\
(\mathrm{~mm})\end{array}$ & $\begin{array}{c}L_{y} \\
(\mathrm{~mm})\end{array}$ & \\
\hline PV3 & 26.6 & -2.3 & 0.483 & 662 & 3.3 & 50 & 0.483 & 662 & 3.3 & 50 & 1:00:00 \\
\hline PV11 & 15.6 & -2.6 & 1.79 & 235 & 6.35 & 50 & 1.31 & 235 & 5.44 & 50 & 1:00:00 \\
\hline A2 & 41.2 & -2.1 & 1.193 & 463 & 15 & 189 & 1.193 & 463 & 15 & 189 & 1:00:00 \\
\hline $\mathrm{A} 3$ & 41.6 & -1.94 & 1.789 & 447 & 20 & 189 & 1.789 & 447 & 20 & 189 & 1:00:00 \\
\hline
\end{tabular}
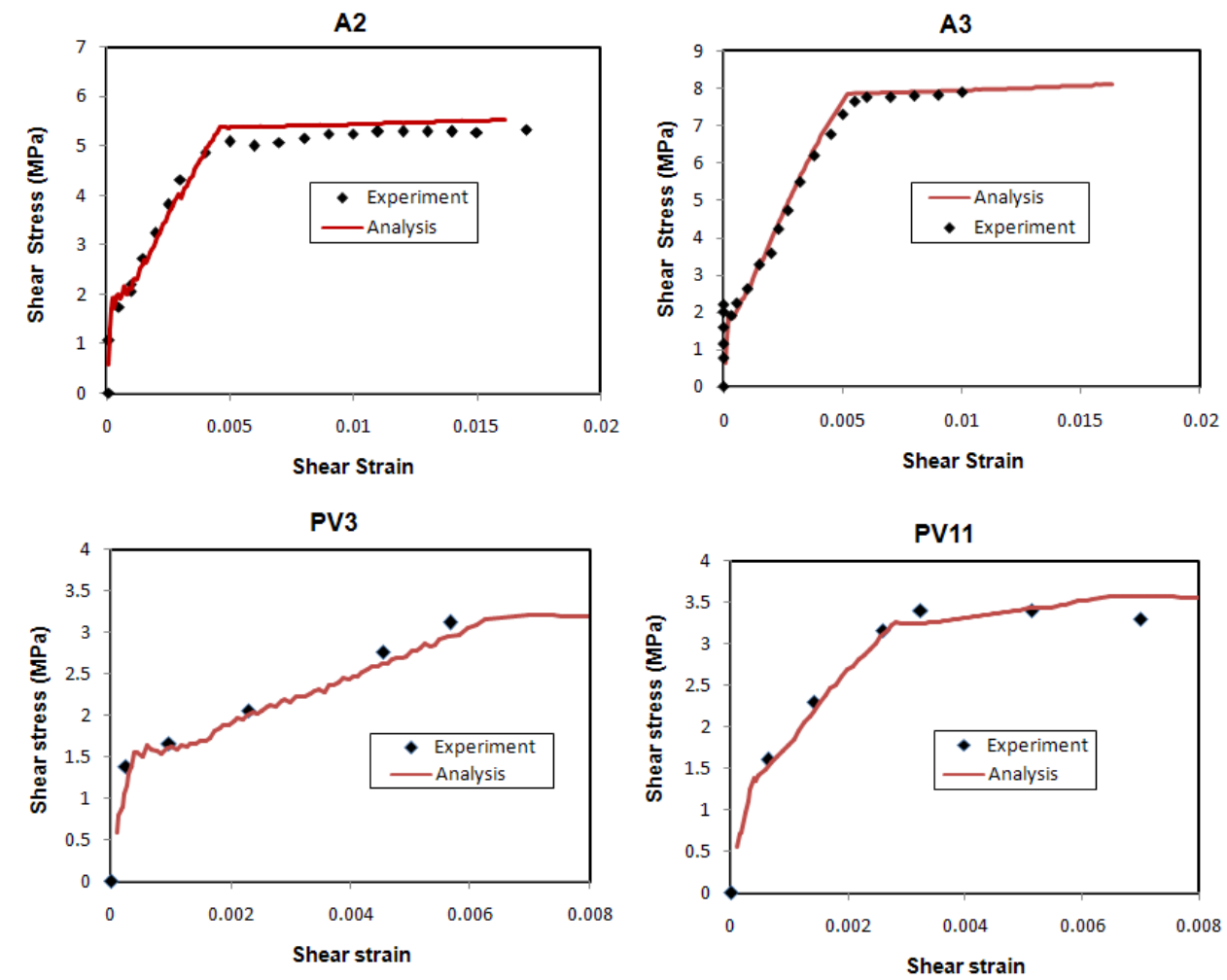

Fig. 4 Comparison with experimental results (A2,A3) by Pang and Hsu (1995) and (PV3,PV11) by Vecchio and Collins (1982).

where, the right hand side of this equation shows the effects of applied axial stress in y direction and also the contribution of concrete (in tension and shear) and reinforcing bars (axial and dowel) to the shear capacity. The interesting point in this type of formulation is the elimination of the effect of other component of applied forces, $\left(\sigma_{x}\right)$, on the shear failure capacity. The effect of this term is indirectly considered in the crack inclination. Also in the average form, this equilibrium is derived as:

$$
\tau_{x y}=\sigma_{1} \cot \theta+\tau_{12}+\rho_{y} \bar{f}_{y}-\sigma_{y} \cot \theta
$$

Figure 6 shows the analytical result for RC Panel PV11, in terms of average stress between cracks (Fig. 6a) and the stresses at the crack faces (Fig. 6b). The large participation of concrete (normal and across cracks) in the shear capacity of this element is obvious. This concrete contribution is the term, which is entirely neglected in the original truss model, where the shear capacity is considered totally equal to the yielding capacity of transverse reinforcing bars. This term is roughly considered in the present design codes and mostly independent of the reinforcement ratio, reinforcement and crack inclination and the size of structures.

This figure obviously shows that even after yielding of transverse reinforcing bars, considerably large stresses can be transferred through combined contribution of longitudinal reinforcement and cracked concrete.

Up to yielding of transverse reinforcing bars, almost the shear stress across cracks is zero. This has substantial meaning; both rotating crack approach (crack stress free method like MCFT) and fixed crack model tend to produce the same results as the cases of fairly isotropic RC elements. After yielding of the transverse reinforcing bars the shear stress across cracks increases to bal- 

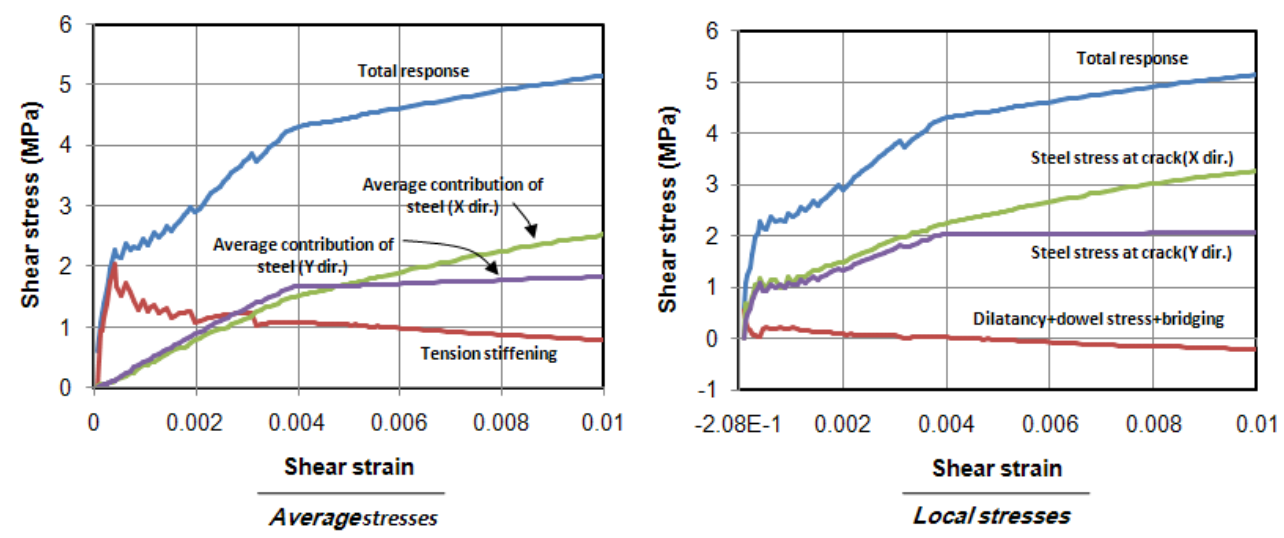

Fig. 5 Contribution of different mechanisms to the overall response of panel PV11.

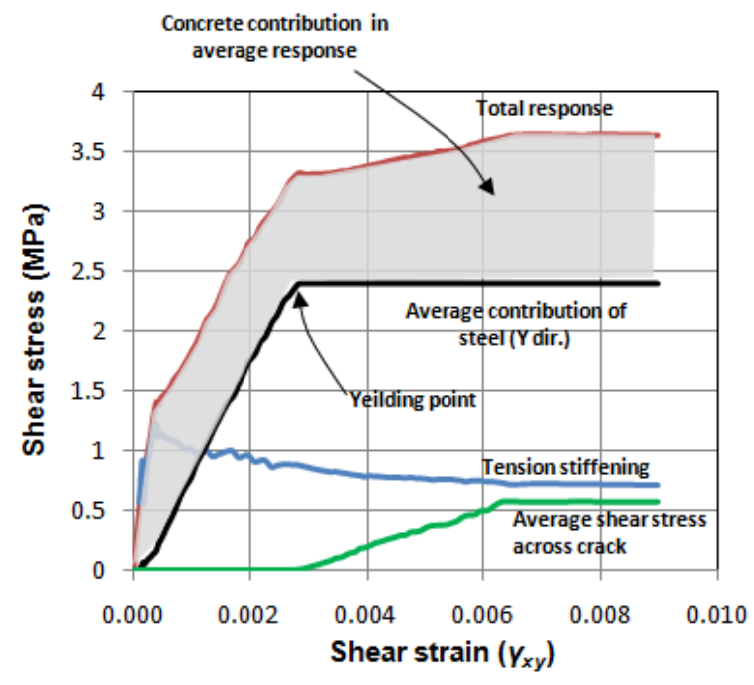

Average stresses

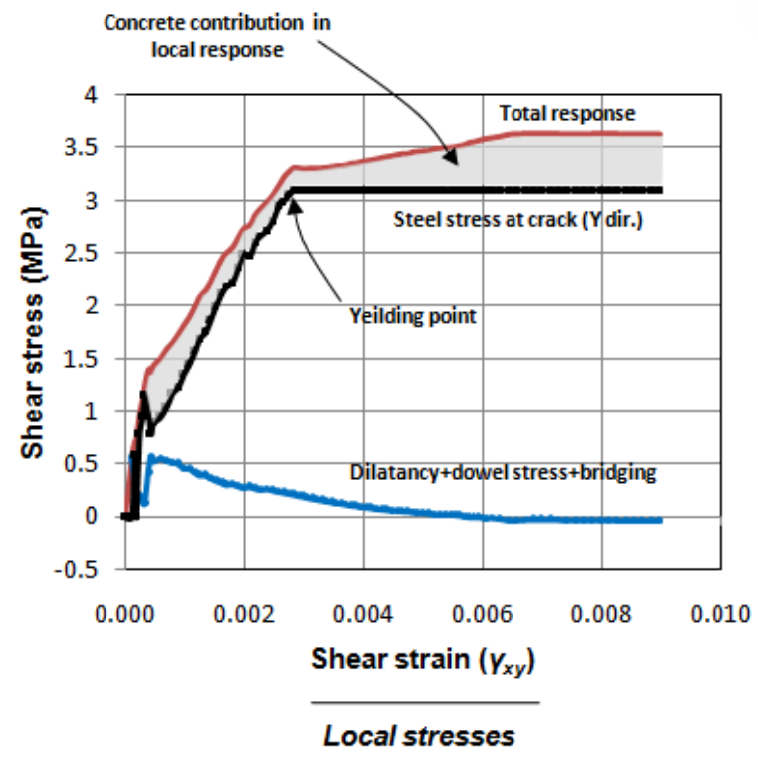

Fig. 6 Contribution of different mechanisms to the overall response of panel PV11 (equilibrium equations in $y$ direction).

ance the difference of stress at crack location as well as between cracks. However after yielding of reinforcing bars in both directions, the shear stress almost remains constant and shear slip and crack opening rapidly increase up to failure of the element.

\section{Derivation of the relations}

It is well known that the cracked reinforced concrete transmits loads in a relatively complex manner involving opening and closing the cracks, slipping of the crack surfaces, new cracks formation, shear transfer at the crack surface, and significant variation of the steel stresses due to bond effect. A rational design method should consider all these parameters and their effects on the shear strength of RC members. The local stress field approach can consider all the influencing parameters on the shear behavior and strength of RC members and can simulate the shear failure response accurately.

Here it is assumed that the shear capacity of concrete is a function of tensile strength $\left(f_{t}\right)$, maximum aggregate size $\left(a_{g}\right)$, crack width $(\omega)$ and spacing $\left(S_{\theta}\right)$, and crack slippage $(\delta)$ :

$$
v_{c}=f_{1}\left(f_{t}, f_{c}^{\prime}\right) \times f_{2}\left(a_{g}\right) \times f_{3}(\omega, \delta) \times f_{4}\left(S_{\theta}\right)
$$

Based on the researches conducted by several authors, including (Walraven 1981), the shear capacity of RC elements increase with increasing the maximum aggregate size. But in high strength concrete, as the cracks pass through the aggregates, the aggregate interlock is not effective in shear transmitting ability of concrete. Crack width and slippage are two other important factors affecting the shear capacity of RC elements. Increasing in crack width and slippage results in decrease in shear capacity of elements (Li et al. 1998; Bujadham and Maekawa 1992). To account for this effect, a parameter called "Crack Deformation Parameter $\left(\mathrm{S}_{\mathrm{c}}\right)$ " is defined as the product of the local longitudinal strain and the crack spacing. Longitudinal strain in the member is a representative of loading conditions and average crack widths along the element. Therefore longitudinal 
strain together with the crack spacing can explicitly consider the effects of crack width and slipping in the shear strength of reinforced concrete elements. This results in modification of Eq. 6 to:

$$
v_{c}=f_{1}\left(f_{t}, f_{c}^{\prime}\right) \times f_{2}\left(a_{g}\right) \times f_{5}\left(S_{c}\right)
$$

Considering Eq. 7, in order to develop a rational and simple relation for shear failure assessment of $\mathrm{RC}$ members, a systematic parametric study is conducted on $\mathrm{RC}$ elements under different conditions of loading and material properties and the effect of these parameters on the contribution of cracked concrete to the shear strength of RC elements is studied. The variation of shear capacity of concrete $\left(v_{\mathrm{c}}\right)$ by increasing the crack deformation parameter is shown in Fig. 7. The effect of maximum aggregate size and tensile strength of concrete is also shown in Fig. 8. This study resulted in Eq. (8) for deformed bars:

$$
v_{c}=0.012 f_{c}^{0.67} \sqrt{a_{g}} S_{c}^{-0.65} \leq f_{t}
$$

and in Eq.(9) for welded wire mesh:

$$
v_{c}=0.0083 f_{c}^{0.67} \sqrt{a_{g}} S_{c}^{-0.65} \leq f_{t}
$$

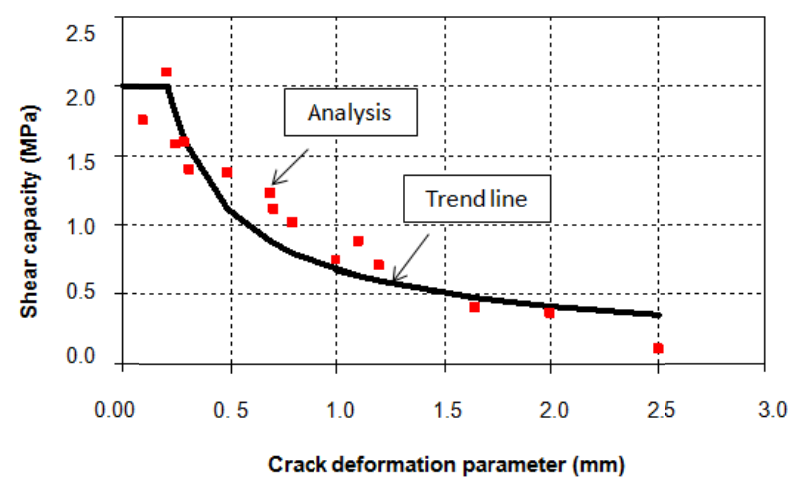

Fig. 7 Shear capacity of RC members that failed before yeilding of longitudinal bars.
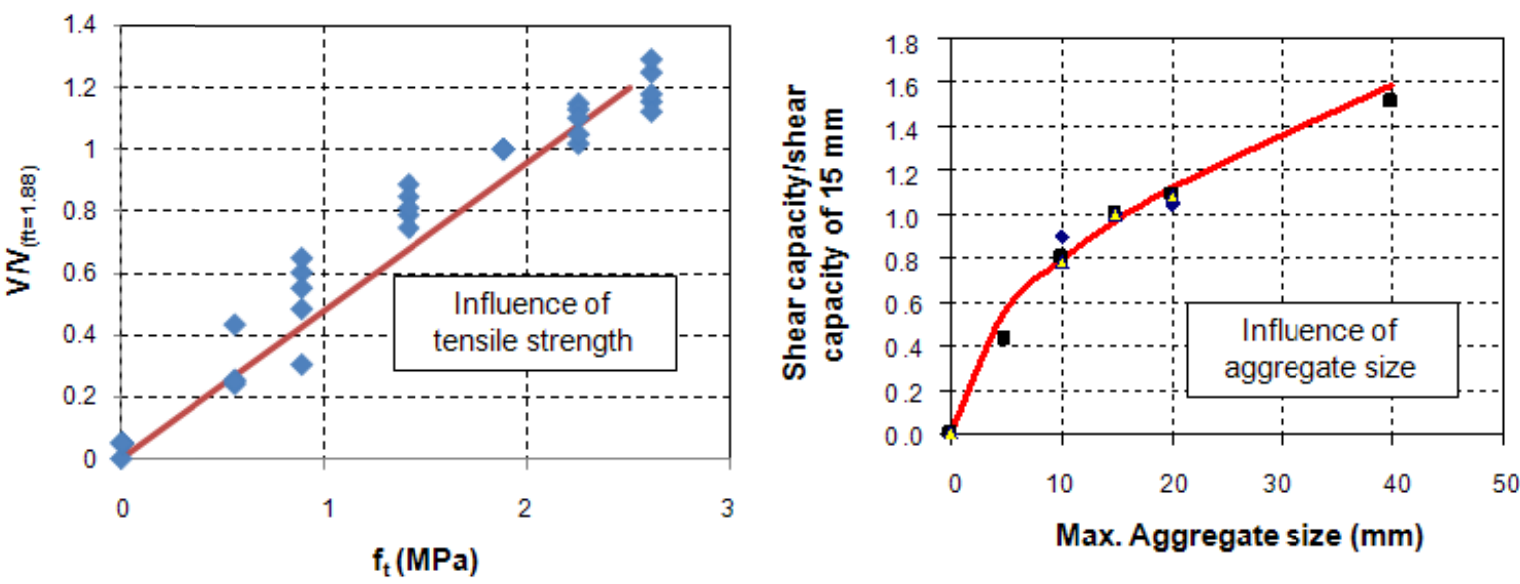

where $f_{\mathrm{c}}$ is the concrete compressive strength (MPa), $a_{g}$ is maximum aggregate size $(\mathrm{mm})$, and $S_{\mathrm{c}}$ is the crack deformation parameter $(\mathrm{mm})$. As the shear capacity of RC members is defined in terms of compressive strength of concrete in most design codes, the tensile strength of concrete in Eq. 7 is substituted with its equivalent value in terms of compressive strength, $f_{t}=0.194 f_{c}^{0.67}$ (Maekawa et al. 2003), in Eq. 8 and Eq. 9. The specialty of these equations is that they can be simply used for any material properties, reinforcement ratio and distribution and also any size of elements.

The experimental tests performed on RC columns (Preistley et al. 1992) showed that shear failure may occur before or after the formation of flexural hinges, which limits the ductility of the flexural behavior of the member. As plastic hinge rotations increase, the widening of cracks reduces the shear capacity because of the reduction of aggregate interlock shear transfer. To investigate the applicability of the proposed relation (Eq. 8) for the RC elements in which the shear failure occurs after yielding of the longitudinal bars, the response of some RC elements with this condition is drawn together with the curves of the $\mathrm{RC}$ elements in which the shear failure occurs prior to yielding of longitudinal bars in Fig. 9. The peak value of each curve can be explained as the shear strength of the element. It can be seen that the proposed relation (Eq. 8) is also correct for these elements. Accuracy of the proposed relation to predict the shear capacity of RC members that failed after longitudinal reinforcements yielding shows that the proposed method is capable of predicting the governing behavior and ductility of RC members.

In high strength and lightweight concrete, the cracks pass through the aggregate, making the crack surfaces smooth, and so the aggregate size will not influence the crack roughness. To apply the Eq. 8 and Eq. 9 to members made of these types of concrete, the effective aggregate size should be used. It is proposed to use the actual value of maximum aggregate size for concrete elements with compressive strength of lower than 60 $\mathrm{MPa}$, and to use a value of $4 \mathrm{~mm}$ for lightweight con-

Fig. 8 Influence of tensile strength and aggregate size on shear capacity. 


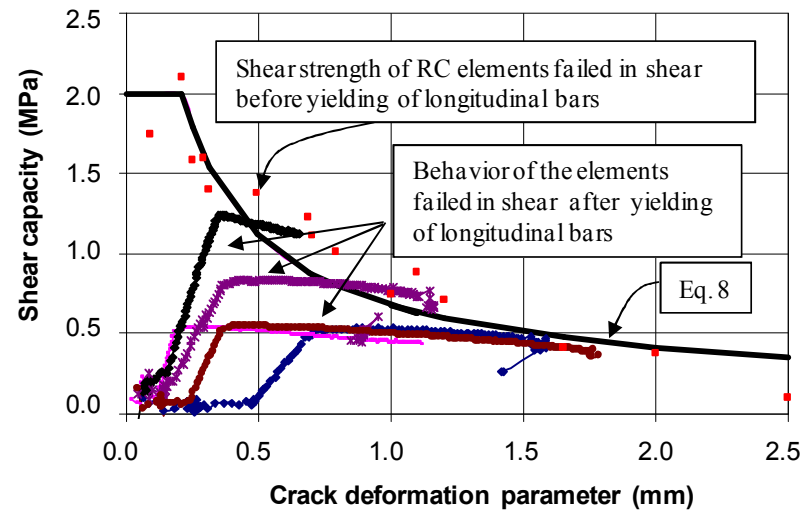

Fig. 9 Shear capacity of RC members that failed after yeilding of longitudinal bars.

crete elements as well as high strength concrete elements with compressive strengths of more than $70 \mathrm{MPa}$. For concrete elements with compressive strengths of between these values, linear interpolation is adopted.

As it is discussed before, the crack deformation parameter, $S_{c}$, is calculated as the product of the local axial strain and crack spacing:

$$
\begin{aligned}
& S_{c}=\varepsilon_{x} \times S_{\theta} \\
& S_{\theta}=\frac{1}{\left(\sin \theta / S_{x}\right)+\left(\cos \theta / S_{y}\right)}
\end{aligned}
$$

where $\varepsilon_{x}$ is longitudinal strain, $S_{\theta}$ is average crack spacing normal to cracks and $S_{x}$ and $S_{y}$ are crack spacing in $\mathrm{x}$ and $\mathrm{y}$ directions, respectively.

The longitudinal strain $\left(\varepsilon_{x}\right)$ in the RC elements can be calculated as follows:

$$
\varepsilon_{x}=\frac{N_{u}+V_{u} \cot \theta}{E_{s} A_{s x}}
$$

where $N_{\mathrm{u}}$ and $V_{\mathrm{u}}$ are axial and shear forces acting on $\mathrm{RC}$ element respectively. $E_{\mathrm{s}}$ is the steel modulus of elasticity and $A_{\mathrm{sx}}$ is area of reinforcing bars in the longitudinal $(x)$ direction. This relation has a good accuracy in predicting the longitudinal strain of RC elements which will be verified in the next section.

Salem (1998) proposed a relation for calculating the crack spacing in RC elements. The simplified form of this equation is adopted here:

$$
L_{e}=1.76 \times \rho^{-0.5} f_{y}^{0.1} f_{c}^{1-0.4} d\left(1+f_{t}\right)
$$

where, $L_{e}$ is the crack spacing in mm, $\rho$ is the reinforcement ratio in the direction under investigation, $f_{y}$ is the reinforcing bar yield stress in $\mathrm{MPa}, d$ is the bar diameter in $\mathrm{mm}, f_{c}^{\prime}$ is the concrete compressive strength in $\mathrm{MPa}$ and $f_{t}$ is the concrete tensile strength in $\mathrm{MPa}$.

Having calculated the longitudinal strain and crack spacing, the crack deformation parameter can be com-

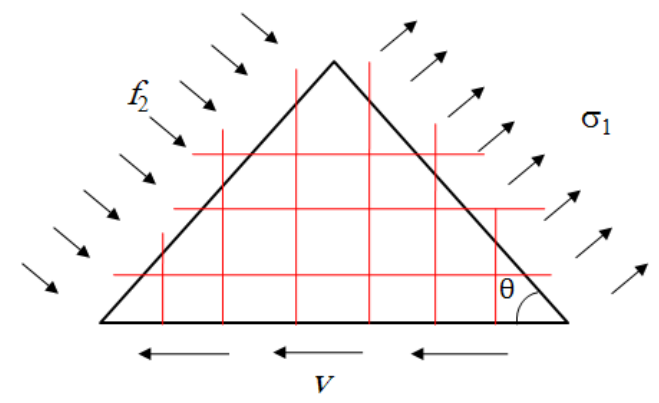

Fig 10 State of stresses in cracked RC element.

puted and then the shear capacity of RC element can be achieved by using Eq. 8 or Eq. 9 .

The transverse steel contribution $\left(v_{\mathrm{s}}\right)$ can be computed by the conventional relation as follows:

$$
v_{s}=\rho_{v} f_{y v} \cot \theta
$$

where $\rho_{v}$ and $f_{v v}$ are the reinforcement ratio and steel yield stress in transverse direction, respectively. Depending upon the concrete and steel properties and the reinforcement ratio, the compressive failure of the concrete may occur before yielding of the transverse reinforcing bars and so the contribution of transverse steel will be less than the value obtained by Eq. 14. Using this equation in such conditions leads to overestimating the contribution of steel bars to the shear capacity of reinforced concrete members. To consider this effect, the equilibrium equation between stresses acting on an $\mathrm{RC}$ element can be considered (Fig. 10):

$$
v=v_{c}+v_{s}=\left(f_{2}+\sigma_{1}\right) \sin \theta \cos \theta
$$

where $\theta$ is the crack direction (Fig. 3), $f_{2}$ is absolute value of concrete compressive stress and $\sigma_{1}$ is concrete tensile stress. At the ultimate condition, the concrete stress, $f_{2}$, will be equal to the compressive strength of the element, $f_{2 \max }$, and the contribution of $\sigma_{1}$, in Eq. 15 becomes small in comparison to the value of $f_{2}$, and can be conservatively neglected. Thus,

$$
v=v_{c}+v_{s}=f_{2 \max } \sin \theta \cos \theta
$$

So the maximum local stress of transverse reinforcing bars is:

$$
v_{s}=f_{2 \max } \sin \theta \cos \theta-v_{c}
$$

The tensile strain in the crack plane weakens the ability of concrete to withstand compression in the direction perpendicular to the crack surface. So the value of $f_{2 \max }$ will be less than the concrete compressive strength because of tensile strains in the crack surface. Based on the experimental tests on reinforced concrete elements, Vecchio and Collins (1986) proposed the following relation to compute the maximum strength of cracked concrete $\left(f_{2 \max }\right)$ : 


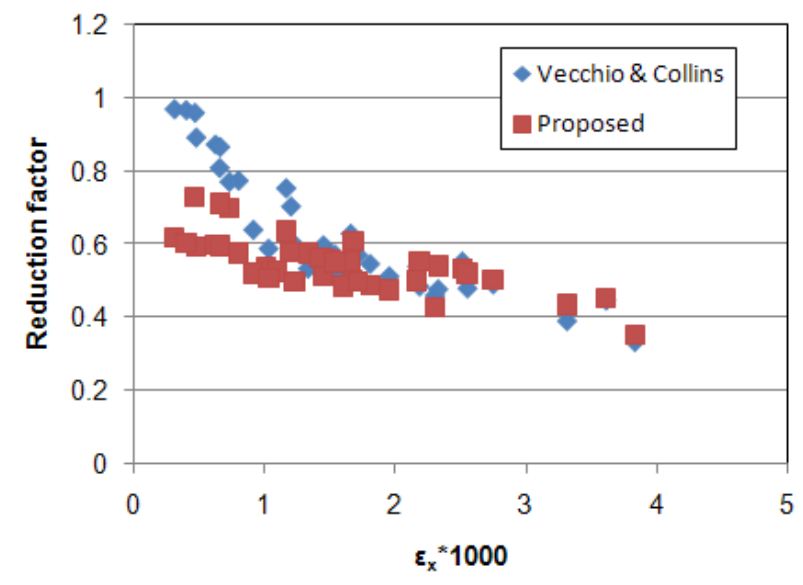

Fig. 11 Concrete compressive strength reduction factors.

$$
f_{2 \max }=\frac{f^{\prime}{ }_{c}}{0.8+170 \varepsilon_{1}}
$$

Computing the value of $\varepsilon_{1}$ can be done based on the following equation:

$$
\varepsilon_{1}=\varepsilon_{x}+\left(\varepsilon_{x}+\varepsilon_{2}\right) \cot ^{2} \theta
$$

replacing $\varepsilon_{1}$ in Eq. 18 by Eq. 19, it can be expressed as:

$$
f_{2 \max }=\frac{2 \sin ^{2} \theta}{\left(1.6 \sin ^{2} \theta+340 \varepsilon_{2} \cos ^{2} \theta\right)+340 \varepsilon_{x}} f^{\prime}{ }_{c}
$$

As the value of $1.6 \sin ^{2} \theta+340 \varepsilon_{2} \cos ^{2} \theta$ is approximately equal to 1 , this equation can be expressed as follows:

$$
f_{2 \max }=\frac{2 \sin ^{2} \theta}{1+340 \varepsilon_{x}} f_{c}^{\prime}
$$

The reduction factors computed with Eq. 21 in comparison to the values obtained with Eq. 18 is shown in Fig. 11 for $42 \mathrm{RC}$ panels. It can be seen that the reduction factors obtained with the proposed relation are almost in a good correspondence with the values obtained with Eq. 21 and also it highly simplifies the design process.

\section{Strength predictions for RC elements}

Among different available experimental results, $42 \mathrm{RC}$ elements (Bentz et al. 2006) with different properties under pure shear or shear combined with axial stress loading are selected to investigate the accuracy of the shear strengths predicted with the proposed method. The properties of the elements and the shear strengths predicted with the MCFT method (Collins et al. 1996), ACI 318-05 method, and the proposed method are shown in

\begin{tabular}{|c|c|c|c|c|c|c|c|c|c|c|c|c|c|c|c|c|c|}
\hline \multicolumn{11}{|c|}{ Zhang \& $H s u, G_{\max }=13 \mathrm{~mm}$} & \multicolumn{3}{|c|}{ Calculations } & & \multicolumn{3}{|c|}{ Vexp./Vcomp. } \\
\hline Panel & $\begin{array}{c}f_{c}^{\prime} \\
(\mathrm{MPa})\end{array}$ & $\begin{array}{c}\rho_{x} \\
(\%)\end{array}$ & $\begin{array}{c}d_{b x} \\
(\mathrm{~mm})\end{array}$ & $\begin{array}{c}f_{y x} \\
(\mathrm{MPa})\end{array}$ & $\begin{array}{c}L_{x} \\
(\mathrm{~mm})\end{array}$ & $\begin{array}{c}\rho_{y} \\
(\%)\end{array}$ & $\begin{array}{c}d_{b y} \\
(\mathrm{~mm})\end{array}$ & $\begin{array}{c}f_{y y} \\
(\mathrm{MPa})\end{array}$ & $\begin{array}{c}L_{y} \\
(\mathrm{~mm})\end{array}$ & $f_{x} / v$ & $\begin{array}{c}S_{\theta} \\
(\mathrm{mm})\end{array}$ & $\begin{array}{c}\varepsilon_{x} \\
(\mathrm{x} 1000\end{array}$ & $\begin{array}{c}S_{c} \\
(\mathrm{~mm})\end{array}$ & $\begin{array}{c}\text { Vexp. } \\
/ \mathrm{f}_{c}\end{array}$ & $\begin{array}{c}\text { Full } \\
\text { MCFT }\end{array}$ & $\mathrm{ACI}$ & $\begin{array}{l}\text { Prop. } \\
\text { Method }\end{array}$ \\
\hline VA1 & 95.1 & 1.19 & 11.3 & 445 & 94 & 0 & 11.3 & 445 & 94 & 0 & 192 & 2.51 & 0.48 & 0.068 & 1.04 & 0.75 & 1.00 \\
\hline VA2 & 98.2 & 2.39 & 16 & 409 & 94 & 0 & 16 & 409 & 94 & 0 & 208 & 2.16 & 0.45 & 0.103 & 1.03 & 1.02 & 0.92 \\
\hline VA3 & 94.6 & 3.59 & 19.5 & 455 & 94 & 0 & 19.5 & 455 & 94 & 0 & 231 & 2.3 & 0.53 & 0.163 & 0.94 & 1.59 & 0.90 \\
\hline VA4 & 103.1 & 5.24 & 25.2 & 470 & 94 & 0 & 25.2 & 470 & 94 & 0 & 200 & 2.33 & 0.46 & 0.22 & 1 & 2.21 & 0.89 \\
\hline VB1 & 98.2 & 2.39 & 16 & 409 & 94 & 0 & 11.3 & 409 & 94 & 0 & 152 & 1.16 & 0.18 & 0.08 & 1.01 & 0.91 & 1.07 \\
\hline VB2 & 97.6 & 3.59 & 19.5 & 455 & 94 & 0 & 11.3 & 455 & 94 & 0 & 158 & 0.47 & 0.07 & 0.097 & 0.95 & 1.1 & 1.09 \\
\hline VB3 & 102.3 & 5.98 & 25.2 & 445 & 94 & 0 & 11.3 & 445 & 94 & 0 & 159 & 0.31 & 0.05 & 0.099 & 0.9 & 1.17 & 1.04 \\
\hline VB4 & 96.9 & 1.79 & 19.5 & 455 & 188 & 0 & 11.3 & 455 & 188 & 0 & 190 & 0.62 & 0.12 & 0.052 & 0.97 & 0.85 & 1.01 \\
\hline & & & & & & & & & & & & & & Ave. & 0.98 & 1.20 & 0.99 \\
\hline
\end{tabular}
Table 2 to Table 5 .

The ACI code expression for the capacity of the

\begin{tabular}{|c|c|c|c|c|c|c|c|c|c|c|c|c|c|c|c|c|c|}
\hline \multicolumn{10}{|c|}{ Vecchio et al., $G_{\max }=10 \mathrm{~mm}$} & \multicolumn{5}{|c|}{ Calculations } & \multicolumn{3}{|c|}{ Vexp./Vcomp. } \\
\hline Panel & $\begin{array}{c}f_{c}^{\prime} \\
(\mathrm{MPa})\end{array}$ & \begin{tabular}{|c|}
$\rho_{x}$ \\
$(\%)$
\end{tabular} & $\begin{array}{c}d_{b x} \\
(\mathrm{~mm})\end{array}$ & $\begin{array}{c}f_{y x} \\
(\mathrm{MPa})\end{array}$ & $\begin{array}{c}L_{x} \\
(\mathrm{~mm})\end{array}$ & $\begin{array}{c}\rho_{y} \\
(\%)\end{array}$ & $\begin{array}{c}d_{b y} \\
(\mathrm{~mm})\end{array}$ & $\begin{array}{c}f_{y y} \\
(\mathrm{MPa})\end{array}$ & \begin{tabular}{|c|}
$L_{y}$ \\
$(\mathrm{~mm})$
\end{tabular} & $\begin{array}{c}S_{\theta} \\
(\mathrm{mm})\end{array}$ & $\begin{array}{c}\varepsilon_{x} \\
(\mathrm{x} 1000)\end{array}$ & $\begin{array}{c}S_{c} \\
(\mathrm{~mm})\end{array}$ & $f_{x} / v$ & $\begin{array}{c}\text { Vexp. } \\
/ \mathrm{f}_{c}^{\prime}\end{array}$ & \begin{tabular}{|c|} 
Full \\
MCFT
\end{tabular} & $\mathrm{ACI}$ & $\begin{array}{l}\text { Prop. } \\
\text { Method }\end{array}$ \\
\hline PA1 & 49.9 & 1.65 & 8 & 522 & 45 & 0.82 & 5.72 & 522 & 45 & 98 & 1.71 & 0.17 & 0 & 0.126 & 0.94 & 0.95 & 0.93 \\
\hline PA2 & 43 & 1.65 & 8 & 522 & 45 & 0.82 & 5.72 & 522 & 45 & 94.2 & 1.45 & 0.14 & 0 & 0.145 & 0.94 & 0.96 & 0.95 \\
\hline PHS1 & 72.2 & 3.23 & 8 & 606 & 44 & 0 & 5.72 & 521 & 44 & 138 & 0.4 & 0.06 & 0 & 0.037 & 1.07 & 0.97 & 0.82 \\
\hline PHS2 & 66.1 & 3.23 & 8 & 606 & 44 & 0.41 & 5.72 & 521 & 44 & 103 & 0.47 & 0.05 & 0 & 0.093 & 1.13 & 1.27 & 1.18 \\
\hline PHS3 & 58.4 & 3.23 & 8 & 606 & 44 & 0.82 & 5.72 & 521 & 44 & 93.6 & 0.66 & 0.06 & 0 & 0.14 & 0.99 & 1.2 & 1.15 \\
\hline PHS8 & 55.9 & 3.23 & 8 & 606 & 44 & 1.24 & 5.72 & 521 & 44 & 92.1 & 1.22 & 0.11 & 0 & 0.193 & 1.02 & 1.45 & 1.19 \\
\hline $\mathrm{PC} 1$ & 25.1 & $\mid 1.65$ & 5.72 & 500 & 44.5 & 0 & 5.72 & 500 & 89 & 88.6 & 1.54 & 0.14 & 0 & 0.197 & 0.84 & 0.99 & 0.88 \\
\hline & & & & & & & & & & & & & & Ave. & 0.99 & 1.11 & 1.01 \\
\hline
\end{tabular}

Table 2 Zhang and Hsu (1998) experimental results.

Table 3 Vecchio et al. (1994) and Vecchio and Chan (1990) experimental results. 
Table 4 Pang and Hsu (1995) experimental results.

\begin{tabular}{|c|c|c|c|c|c|c|c|c|c|c|c|c|c|c|c|c|c|}
\hline \multicolumn{10}{|c|}{ Pang \& Hsu, $G_{\max }=19 \mathrm{~mm}$} & \multicolumn{5}{|c|}{ Calculations } & \multicolumn{3}{|c|}{ Vexp./Vcomp. } \\
\hline Panel & $\begin{array}{c}f_{c}^{\prime} \\
(\mathrm{MPa})\end{array}$ & $\begin{array}{c}\rho_{x} \\
(\%)\end{array}$ & $\begin{array}{c}d_{b x} \\
(\mathrm{~mm})\end{array}$ & $\begin{array}{c}f_{y x} \\
(\mathrm{MPa})\end{array}$ & $\begin{array}{c}L_{x} \\
(\mathrm{~mm})\end{array}$ & $\begin{array}{c}\rho_{y} \\
(\%)\end{array}$ & $\begin{array}{c}d_{b y} \\
(\mathrm{~mm})\end{array}$ & $\begin{array}{c}f_{y y} \\
(\mathrm{MPa})\end{array}$ & $\begin{array}{c}L_{y} \\
(\mathrm{~mm})\end{array}$ & $\begin{array}{c}S_{\theta} \\
(\mathrm{mm})\end{array}$ & $\begin{array}{c}\varepsilon_{x} \\
(\mathrm{x} 1000) \\
\end{array}$ & $\begin{array}{c}S_{c} \\
(\mathrm{~mm})\end{array}$ & $\begin{array}{l}f_{x} \\
/ v\end{array}$ & $\begin{array}{l}\text { Vexp. } \\
/ \mathrm{f}_{c}^{\prime}\end{array}$ & $\begin{array}{c}\text { Full } \\
\text { MCFT }\end{array}$ & $\mathrm{ACI}$ & $\begin{array}{l}\text { Prop. } \\
\text { Method }\end{array}$ \\
\hline A2 & 41.3 & 1.19 & 16 & 463 & 189 & 1.19 & 16 & 463 & 189 & 215 & 2.75 & 0.59 & 0 & 0.136 & 1.01 & 0.87 & 0.90 \\
\hline A3 & 41.6 & 1.79 & 19.5 & 447 & 189 & 1.79 & 19.5 & 447 & 189 & 232 & 2.55 & 0.59 & 0 & 0.19 & 0.98 & 1.23 & 0.91 \\
\hline A4 & 42.5 & 2.98 & 25.2 & 470 & 189 & 2.98 & 2.5 & 470 & 189 & 224 & 2.28 & 0.51 & 0 & 0.28 & 0.97 & 1.82 & 0.92 \\
\hline B1 & 45.2 & 1.19 & 16 & 463 & 189 & 0.6 & 1.13 & 445 & 189 & 223 & 1.66 & \begin{tabular}{|l|}
0.37 \\
\end{tabular} & 0 & 0.092 & 1.01 & 0.87 & 1.10 \\
\hline B2 & 44.1 & 1.79 & 19.5 & 447 & 189 & 1.2 & 1.6 & 463 & 189 & 222 & 1.95 & 0.43 & 0 & 0.146 & 0.96 & 0.97 & 0.96 \\
\hline B3 & 44.9 & 1.79 & 19.5 & 447 & 189 & 0.6 & 1.13 & 445 & 189 & 222 & 1.20 & 0.27 & 0 & 0.102 & 0.94 & 0.96 & 1.11 \\
\hline B4 & 44.8 & 2.99 & 25.2 & 470 & 189 & 0.6 & 1.13 & 445 & 189 & 223 & 0.80 & 0.18 & 0 & 0.119 & 0.92 & 1.12 & 1.05 \\
\hline B5 & 42.8 & 2.98 & 25.2 & 470 & 189 & 1.2 & 1.6 & 463 & 189 & 226 & 1.23 & 0.28 & 0 & 0.177 & 0.89 & 1.16 & 1.08 \\
\hline B6 & 42.8 & 2.98 & 25.2 & 470 & 189 & 1.79 & 1.95 & 447 & 189 & 222 & 1.68 & 0.37 & 0 & 0.23 & 0.95 & 1.53 & 1.03 \\
\hline & & & & & & & & & & & & & & Ave. & 0.96 & 1.17 & 1.01 \\
\hline
\end{tabular}

Table 5 Vecchio and Collins (1982) experimental results.

\begin{tabular}{|c|c|c|c|c|c|c|c|c|c|c|c|c|c|c|c|}
\hline \multicolumn{9}{|c|}{ Vecchio \& Collins, $G_{\max }=6 \mathrm{~mm}$} & \multicolumn{3}{|c|}{ Calculations } & & \multicolumn{3}{|c|}{ Vexp./Vcomp. } \\
\hline Panel & $\begin{array}{c}f_{c}^{\prime} \\
(\mathrm{MPa})\end{array}$ & $\begin{array}{l}\rho_{x} \\
(\%)\end{array}$ & $\begin{array}{c}f_{y x} \\
(\mathrm{MPa})\end{array}$ & $\begin{array}{c}L_{x} \\
(\mathrm{~mm})\end{array}$ & $\begin{array}{c}\rho_{y} \\
(\%)\end{array}$ & $\begin{array}{c}f_{y y} \\
(\mathrm{MPa})\end{array}$ & $\begin{array}{c}\begin{array}{c}L_{y} \\
(\mathrm{~mm})\end{array} \\
\end{array}$ & $\begin{array}{l}f_{x} \\
/ v\end{array}$ & $\begin{array}{c}S_{\theta} \\
(\mathrm{mm})\end{array}$ & $\begin{array}{c}\varepsilon_{x} \\
(\mathrm{x} 1000)\end{array}$ & $\begin{array}{c}S_{c} \\
(\mathrm{~mm})\end{array}$ & $\begin{array}{l}\text { Vexp. } \\
/ f^{\prime} c\end{array}$ & $\begin{array}{c}\text { Full } \\
\text { MCFT }\end{array}$ & ACI & $\begin{array}{l}\text { Prop. } \\
\text { Method }\end{array}$ \\
\hline PV1 & 34.5 & 1.79 & 483 & 51 & 1.68 & 483 & 54 & 0 & 36.1 & 2.47 & 0.089 & 0.23 & 0.93 & 1.37 & 0.88 \\
\hline PV2 & 23.5 & 0.18 & 428 & 51 & 0.26 & 428 & 50 & 0 & 37.1 & 3.64 & 0.135 & 0.049 & 1.41 & 0.48 & 0.96 \\
\hline PV3 & 26.6 & 0.48 & 662 & 51 & 0.48 & 662 & 50 & 0 & 53 & 3.72 & 0.197 & 0.115 & 0.95 & 0.63 & 0.82 \\
\hline PV4 & 26.6 & 1.03 & 242 & 51 & 1.06 & 242 & 50 & 0 & 60.1 & 1.55 & 0.093 & 0.109 & 1.12 & 0.68 & 0.86 \\
\hline PV5 & 28.3 & 0.74 & 621 & 100 & 0.74 & 621 & 100 & 0 & 72.1 & 3.32 & 0.239 & 0.15 & 0.91 & 0.8 & 0.84 \\
\hline PV6 & 29.8 & 1.79 & 266 & 51 & 1.78 & 266 & 51 & 0 & 36.1 & 1.61 & 0.058 & 0.153 & 0.95 & 0.84 & 0.79 \\
\hline PV10 & 14.5 & 1.79 & 276 & 51 & 1 & 276 & 51 & 0 & 36.1 & 1.01 & 0.037 & 0.27 & 1.06 & 1.05 & 1.08 \\
\hline PV11 & 15.6 & 1.79 & 235 & 51 & 1.31 & 235 & 51 & 0 & 84.8 & 1.00 & 0.085 & 0.23 & 0.98 & 0.9 & 0.91 \\
\hline PV12 & 16 & 1.79 & 469 & 51 & 0.26 & 469 & 51 & 0 & 106 & 0.54 & 0.057 & 0.196 & 1.09 & 1.24 & 1.31 \\
\hline PV16 & 21.7 & 0.74 & 255 & 51 & 0.74 & 255 & 51 & 0 & 36.1 & 1.82 & 0.065 & 0.099 & 1.12 & 0.62 & 0.82 \\
\hline PV18 & 19.5 & 1.79 & 431 & 51 & 0.3 & 431 & 51 & 0 & 36.1 & 0.73 & 0.026 & 0.156 & 1.08 & 1.1 & 1.15 \\
\hline PV19 & 19 & 1.79 & 458 & 51 & 0.46 & 458 & 51 & 0 & 36.1 & 0.92 & 0.033 & 0.21 & 0.95 & 1.1 & 1.23 \\
\hline PV20 & 19.6 & 1.79 & 460 & 51 & 0.57 & 460 & 51 & 0 & 36.1 & 1.03 & 0.037 & 0.22 & 0.93 & 1.04 & 1.18 \\
\hline PV21 & 19.5 & 1.79 & 458 & 51 & 0.86 & 458 & 51 & 0 & 36.1 & 1.34 & 0.048 & 0.26 & 0.91 & 1.14 & 1.06 \\
\hline PV22 & 19.6 & 1.79 & 458 & 51 & 1.4 & 458 & 51 & 0 & 36.1 & 1.70 & 0.061 & 0.31 & 0.98 & 1.38 & 0.95 \\
\hline PV26 & 21.3 & 1.79 & 456 & 51 & 1.02 & 456 & 51 & 0 & 36.1 & 1.53 & 0.055 & 0.25 & 0.88 & 1.18 & 0.97 \\
\hline PV27 & 20.5 & 1.79 & 442 & 51 & 1.79 & 442 & 51 & 0 & 36.1 & 1.76 & 0.063 & 0.31 & 0.96 & 1.41 & 0.96 \\
\hline PV30 & 19.1 & 1.79 & 437 & 51 & 1.09 & 437 & 51 & 0 & 36.1 & 1.54 & 0.055 & 0.27 & 0.88 & 1.18 & 0.93 \\
\hline & & & & & & & & & & & & Ave. & 1.01 & 1.01 & 0.98 \\
\hline
\end{tabular}

members under shear and flexural actions is as follows:

$$
\begin{aligned}
& V_{c}=v_{c} b_{w} d \\
& v_{c}=0.17 \sqrt{f_{c}}
\end{aligned}
$$

In using this expression for elements made from highstrength concrete, the term $\sqrt{f_{c}}$ is limited to a value of 8.8 MPa.

The average ratio of the predicted strengths to the experimental ones for these 42 elements with the ACI 31805 method is 1.10 , with the full MCFT method is 0.99 , and with the proposed method is 1.00 . As it is shown, the ACI 318-05 method predicts the strengths in some cases so un-conservative. The MCFT method in its full format, predicts the strengths accurately, but it is hard to use for design processes. Because of this problem, Bentz et al. (2006) proposed a simplified form of the
MCFT that is more simple to apply for design, but the results are less accurate in predicting the shear strengths (the average of ratio of shear strengths predicted for selected elements to the experimental results is equal to 1.11). It is also shown that the proposed method is simple and gives accurate results in comparison to experimental results.

To control the accuracy of Eq. 12 for calculating the longitudinal strain in $\mathrm{RC}$ elements, the obtained longitudinal strain is compared with the longitudinal strain correspondent to the shear strength of some RC elements in Table 6.

\section{Application to design of RC members}

The proposed method is also applicable for design of RC members. For computing the crack spacing of reinforced concrete members, the CEB-FIP relation can be 
Table 6 Computed longitudinal strains for some RC elements.

\begin{tabular}{|c|c|c|}
\hline Panel & $\begin{array}{c}\text { Expected } \\
\text { Longitudinal Strain }\end{array}$ & $\begin{array}{c}\text { Computed } \\
\text { Longitudinal Strain }\end{array}$ \\
\hline PV3 & 0.0024 & 0.00383 \\
\hline PV4 & 0.0013 & 0.00167 \\
\hline PV11 & 0.0009 & 0.001 \\
\hline PV27 & 0.0015 & 0.00149 \\
\hline A2 & 0.00261 & 0.00273 \\
\hline A3 & 0.0029 & 0.00254 \\
\hline B1 & 0.00164 & 0.00161 \\
\hline B2 & 0.00194 & 0.00191 \\
\hline
\end{tabular}
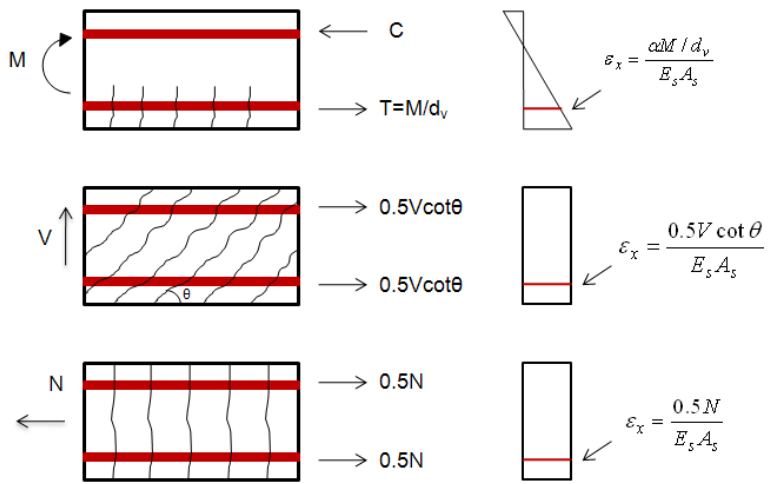

Fig. 12 Computation of longitudinal strain in the member.

used, which describes the average crack spacing as a function of the bar diameter, reinforcement ratio, concrete cover and spacing between bars:

$$
L_{a v}=2\left(c+\frac{S_{\circ}}{10}\right)+k_{1} k_{2} \frac{d_{b}}{\rho}
$$

where $c$ is the clear cover, $S_{\circ}$ is the spacing between center of bars, $k_{1}$ is coefficient equal to 0.4 for deformed bars and 0.8 for smooth bars, $k_{2}$ is coefficient to account for strain gradient which equals to 0.25 for pure tension and 0.125 for bending, $d_{b}$ is bar diameter and $\rho$ is effective reinforcement ratio which can be calculated according to the given instructions in the next section. by:

The longitudinal strain $\left(\varepsilon_{x}\right)$ in $\mathrm{RC}$ members is given

$$
\varepsilon_{x}=\frac{0.5 N_{u}+\alpha M_{u} / d+0.5 V_{u} \cot \theta}{E_{s} A_{s x}}
$$

where $E_{s}$ is the steel modulus of elasticity, $A_{s x}$ is the steel area in the flexural tension zone, $\mathrm{d}$ is the effective depth of the section, $N_{u}$ is the factored applied axial load (positive if tensile), $M_{u}$ is the factored bending moment (positive), $\alpha$ is longitudinal strain modifier factor that accounts for the average crack width, $V_{u}$ is the factored shear force (positive) and $\theta$ is the crack direction (Fig. 12) and can be calculated as follows:

$$
\tan 2 \theta=\frac{-2 V}{P}
$$

Simplifying this equation results in:

$$
\left\{\begin{array}{l}
\theta=0.5 \arctan \left(\frac{-2 V}{P}\right) \text { if } \frac{-2 V}{P}<0 \\
\theta=\frac{\pi}{2}+0.5 \arctan \left(\frac{-2 V}{P}\right) \text { if } \frac{-2 V}{P} \geq 0
\end{array}\right.
$$

where $V$ is the applied shear force and $P$ is the applied axial force (positive in compression). The conventional form of the Eq. 25 calculates the longitudinal strain in the maximum width of the flexural cracks. But as in the design procedures the average crack spacing is used to calculate the shear capacity of the element, the longitu dinal strain should also be calculated on the basis of the average crack width. The parameter $\alpha$ is used to account for this problem. Based on the conducted parameter study, 0.8 is adopted here for this parameter.

It should be noted that Eq. 12 can be used just before yielding of longitudinal reinforcing bars. Although the general model proposed in Eq. 8 and 9 can also be used for the shear failure assessment of RC elements after yielding of main reinforcing bars as shown in Fig. 9, but for such a case the axial steel strain should be computed based on the member ductility demand which has not been discussed in this paper. Therefore, the design procedure for calculating the shear capacity of RC members can be summarized as follows:

1- Calculating the crack spacing in longitudinal and transverse directions of the member according to Eq. 24 and the instructions given in the next section.

2- Calculating the angle of the cracks according to Eq. 26 and 27.

3- Calculating the average crack spacing normal to cracks using Eq. 11.

4- Calculating the longitudinal strain in the member according to Eq. 25.

5- Calculating the Crack Deformation Parameter, $S_{c}$, according to Eq. 10.

6- Calculating the contribution of concrete to the shear capacity of the member, $V_{c}$, according to Eq. 8 or Eq. 9 depending on the type of the reinforcing bars and using Eq. 22.

7- Calculating the total shear capacity of the member by adding the concrete and steel shear contributions.

\section{Size effect}

The failure of large RC elements during earthquakes resulted in investigations (Bazant and Kim 1984; Walraven and Lehwalter 1994; Kani 1967; Taylor 1972; Kennedy 1967; Shioya et al. 1989), in which it was indicated that when the size of the RC element increases, the shear strength decreases. So using the conventional design process for large RC members leads to overesti- 
mating their strength which may be up to $50 \%$ or more.

In 1967, Kani (1967) showed the importance of the size effect and demonstrated that as the depth of the beam increases, the shear stress at failure decreases. Shioya et al. (1989) reaffirmed this fact with an extensive experimental program conducted in Japan and made a convincing evidence for this phenomenon. The result of this work is shown in Fig. 13, which can be stated that by increasing the member depth or decreasing the maximum aggregate size, the shear stress at failure decreases. Since then, several experimental and analytical researches have been conducted to study the size effect which resulted in this general agreement that the main reason of this phenomenon is the larger crack widths in the larger members.

Until 1980, this so called "size effect" phenomenon was not considered in the design processes. After that, according to the experimental and analytical results, some codes tried to consider this important effect by empirical formulations. Okamura and Hiagai (1980) proposed a design equation for shear strength upon investigation of published test results on shear strength of reinforced concrete beams without web reinforcement. Bazant and Kim (1984) believed that the most important consequence of wider cracks is the reduced residual tensile stresses and proposed a size reduction factor based on nonlinear fracture mechanics to account for this effect. The MCFT method accounts for this effect by computing a parameter which is a function of crack spacing. This method is used in some recent codes such as AASHTO-LRFD (1998), but still most of the design codes such as ACI-318 (2005) do not consider size effect in the design methods, and as the structures are becoming larger in size, a rational design method should be able to consider this important effect appropriately.

In the proposed design method, the size effect is taken into consideration by computing the crack spacing while considering the effective size of RC zone (An et al. 1996). It is well known that the concrete behavior near the reinforcing bars is different from far from. This difference is taken into account by considering two different zones in RC members, one for the concrete near the steel bars, and showing tension-stiffening behavior (called as RC zone), and another one for the concrete outside the RC zone showing strain-softening behavior (called as PL zone). So, the cracking behavior and consequently the shear strength of RC zone and PL zone are different. The size of $\mathrm{RC}$ zone is related to the bond effect, which is related to the diameter and amount of the steel bar and is a very important factor for size effect investigation. As the diameter of the steel bar will not always increase proportionally with the scale of the member, the size of RC zone will not increase consequently. The size of RC zone is related to the bond effect of reinforcing bars and should be decided by the bond characteristics. There are many experimental and analytical researches conducted by several authors to study the bond strength, the area of effective RC zone and bond slip relation of bars. An example of the definition of $\mathrm{RC}$ zone is shown in Fig. 14 (Collins and Mitchell 1991), which is used in the proposed method to calculate the effective area of RC zone. Computing the effective area of $\mathrm{RC}$ zone, the effective ratio of reinforcement can be calculated and then the crack spacing within this zone is calculated. Just a few primary cracks within $\mathrm{RC}$ zone grow to the plain concrete zone, so the spacing between critical unstable cracks is larger than the crack spacing within $\mathrm{RC}$ zone. In order to consider this effect, herein it is assumed that the crack spacing is equal to crack spacing within the RC zone multiplied by the ratio of whole member cross sectional area to the area of $\mathrm{RC}$ zone. If the member has no transverse reinforcement, the crack spacing in y direction should be assumed equal to the member depth. By using this method the crack spacing and consequently the member capacity will be calculated with considering the bond influencing zone of reinforcing bars.

The precision of the proposed method in predicting the shear strength of large beams is shown in the following section. It is shown in Table 7 that even in large beams the predicted shear strength is accurate in comparison with the experimental results.

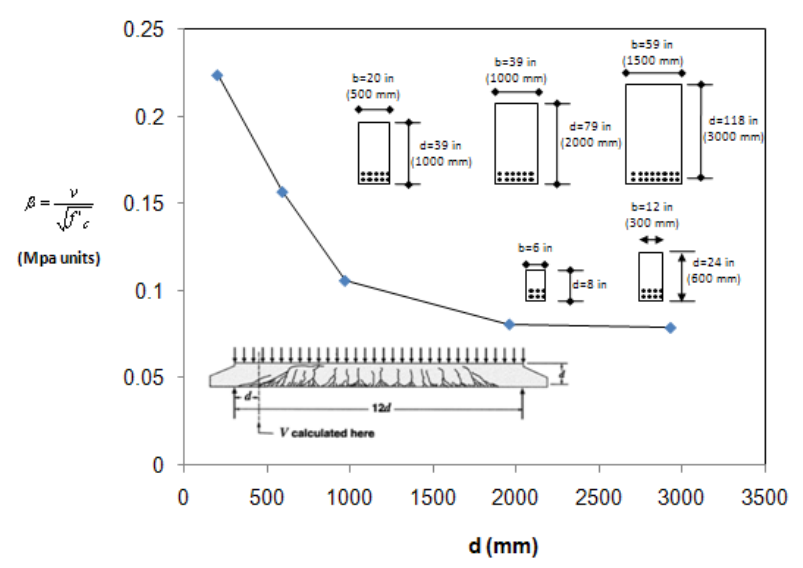

Fig. 13 Influence of member depth and maximum aggregate size on shear stress at failure, tests by Shioya et al. (1989).

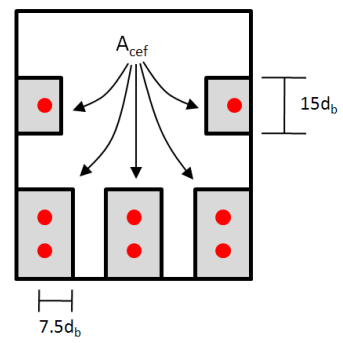

Fig. 14 Definition of RC zone (Collins and Mitchell 1991). 


\section{Strength predictions for RC members}

To study the accuracy of the relations in different conditions like size effect, high strength concrete and bar distribution over the element, the shear capacity of beams (Collins and Kuchma 1999) and columns (Kirschner and Collins 1986) were calculated with the proposed method and the predicted shear strengths are compared with the experiment results in Table 7 and Table 8.

For the case of beams, 17 specimens (Collins and Kuchma 1999) were selected. All the specimens were under a point load at the mid-span, resulting in a shearspan-to-depth ratio of about three. The beams have different depths, reinforcement ratio, and distributions, and all of them failed in shear prior to yielding of the longitudinal reinforcement. In 5 specimens high strength concrete was used. As it is shown in Table 7 the average of the predicted shear strengths with the proposed method is almost 1 (Std. Dev. of 0.095), while the ACI 318-99 method predicts the shear strengths with the average of 0.971 , and the MCFT with the average of 1.204 but with lower standard deviation in comparison to ACI 318-99 method.

For the columns, 24 specimens (Kirschner and Collins 1986) were selected. The parameters that change in specimens are the ratio of compression to shear force, $\mathrm{N} / \mathrm{V}$, the concrete compressive strength, the specimen width, and the amount of shear reinforcement. As it is shown in Table 8 the proposed method can predict the shear strengths precisely with the average of 1.04 (Std. Dev. of 0.18 ), while the average of shear strength predicted by the detailed ACI 318-99 method is 1.03 (Std.
Dev. of 0.4 ), and is 1.31 (Std. Dev. of 0.25 ) for the MCFT method.

It is shown in Table 7 that even in large beams; the predicted shear strength is accurate in comparison with the experimental results.
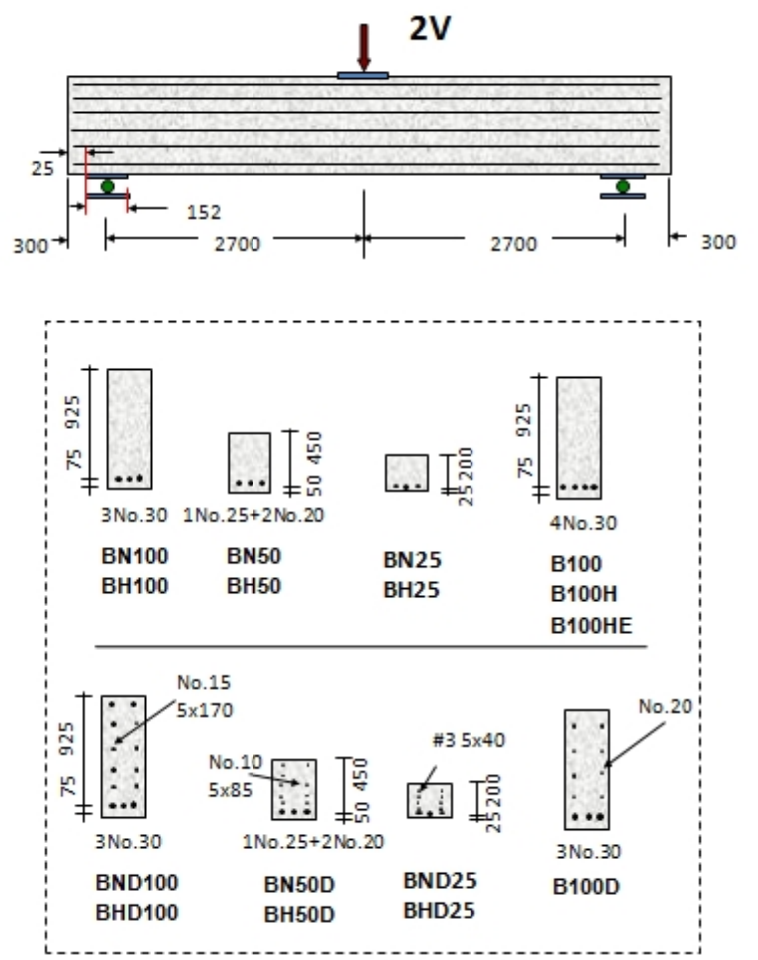

Fig. 15 Details of Collins beams. (Collins and Kuchma 1999)

Table 7 Collins and Kuchma (1999) beams verification.

\begin{tabular}{|c|c|c|c|c|c|c|c|c|c|c|c|c|c|c|c|c|}
\hline \multicolumn{9}{|c|}{ Properties \& geometry } & \multirow{2}{*}{$\begin{array}{c}S_{\theta} \\
\mathrm{mm}\end{array}$} & \multirow{2}{*}{$\begin{array}{c}\varepsilon_{x} \\
(\mathrm{x} 1000)\end{array}$} & \multirow{2}{*}{$\begin{array}{c}S_{c} \\
\mathrm{~mm}\end{array}$} & \multirow{2}{*}{$\begin{array}{l}\text { Comp. } \\
\text { Shear } \\
(\mathrm{kN})\end{array}$} & \multirow{2}{*}{$\begin{array}{l}\text { Exp. } \\
\text { Shear } \\
(\mathrm{kN})\end{array}$} & \multirow{2}{*}{$\begin{array}{l}\text { Vexp./ } \\
\text { Vcomp. }\end{array}$} & \multirow{2}{*}{$\begin{array}{l}\text { Vexp./ } \\
\text { V }_{\text {ACI }}\end{array}$} & \multirow{2}{*}{$\begin{array}{l}\text { Vexp./ } \\
\text { V }_{\text {MCFT }}\end{array}$} \\
\hline Beam & $\begin{array}{c}h \\
(\mathrm{~mm})\end{array}$ & $\begin{array}{c}b \\
(\mathrm{~mm}) \\
\end{array}$ & $\begin{array}{c}d \\
(\mathrm{~mm})\end{array}$ & $\begin{array}{c}f_{c}^{\prime} \\
(\mathrm{MPa}) \\
\end{array}$ & $\begin{array}{c}A_{s} \\
\left(\mathrm{~mm}^{2}\right)\end{array}$ & $\begin{array}{c}\rho_{x} \\
(\%) \\
\end{array}$ & $\begin{array}{c}\rho_{y} \\
(\%)\end{array}$ & $\begin{array}{c}f_{y y} \\
\text { (MPa) }\end{array}$ & & & & & & & & \\
\hline BN100 & 1000 & 300 & 925 & 37.2 & 2100 & 0.76 & 0 & 0 & 60.1 & 0.85 & 0.051 & 186 & 192 & 0.968 & 0.68 & 1.14 \\
\hline BN50 & 500 & 300 & 450 & 37.2 & 1100 & 0.81 & 0 & 0 & 30 & 1.08 & 0.032 & 124 & 132 & 0.941 & 0.96 & 1.33 \\
\hline $\mathrm{BN} 25$ & 250 & 300 & 225 & 37.2 & 600 & 0.89 & 0 & 0 & 14.8 & 1.49 & 0.022 & 78 & 73 & 1.073 & 1.06 & 1.25 \\
\hline $\mathrm{BN} 12$ & 120 & 300 & 110 & 37.2 & 300 & 0.91 & 0 & 0 & 7.5 & 1.84 & 0.014 & 51 & 40 & 1.271 & 1.19 & 1.24 \\
\hline BH100 & 1000 & 300 & 925 & 98.8 & 2100 & 0.76 & 0 & 0 & 60.1 & 0.86 & 0.052 & 191 & 193 & 0.992 & 0.5 & 1.08 \\
\hline BH50 & 500 & 300 & 450 & 98.8 & 1100 & 0.81 & 0 & 0 & 30 & 1.11 & 0.032 & 126 & 132 & 0.951 & 0.7 & 1.2 \\
\hline $\mathrm{BH} 25$ & 250 & 300 & 225 & 98.8 & 600 & 0.89 & 0 & 0 & 14.8 & 1.51 & 0.022 & 80 & 85 & 0.945 & 0.91 & 1.28 \\
\hline BND100 & 1000 & 300 & 925 & 37.2 & 2900 & 1.05 & 0 & 0 & 22.8 & 1.05 & 0.024 & 300 & 258 & 1.162 & 0.91 & 1 \\
\hline BND50 & 500 & 300 & 450 & 37.2 & 1500 & 1.11 & 0 & 0 & 16.5 & 1.17 & 0.019 & 169 & 163 & 1.035 & 1.19 & 1.13 \\
\hline BND25 & 250 & 300 & 225 & 37.2 & 884 & 1.31 & 0 & 0 & 9.7 & 1.37 & 0.013 & 110 & 112 & 0.982 & 1.63 & 1.36 \\
\hline BHD100 & 1000 & 300 & 925 & 98.8 & 2900 & 1.05 & 0 & 0 & 22.8 & 1.07 & 0.024 & 311 & 278 & 1.118 & 0.72 & 0.94 \\
\hline BHD50 & 500 & 300 & 450 & 98.8 & 1500 & 1.11 & 0 & 0 & 16.1 & 1.18 & 0.019 & 177 & 193 & 0.916 & 1.03 & 1.15 \\
\hline BHD25 & 250 & 300 & 225 & 98.8 & 884 & 1.31 & 0 & 0 & 9.8 & 1.49 & 0.013 & 113 & 111 & 1.016 & 1.19 & 1.37 \\
\hline B100 & 1000 & 300 & 925 & 36 & 2800 & 1.01 & 0 & 0 & 60.1 & 0.7 & 0.042 & 205 & 225 & 0.913 & 0.81 & 1.22 \\
\hline B100D & 1000 & 300 & 925 & 36 & 3300 & 1.19 & 0 & 0 & 22.5 & 1.01 & 0.023 & 325 & 320 & 1.015 & 1.15 & 1.21 \\
\hline BM100 & 1000 & 300 & 925 & 47 & 2100 & 0.76 & 0.079 & 508 & 50 & 1.16 & 0.057 & 311 & 342 & 0.909 & 0.8 & 1.39 \\
\hline BM100D & 1000 & 300 & 925 & 47 & 2900 & 1.05 & 0.079 & 508 & 21 & 1.28 & 0.027 & 447 & 461 & 0.969 & 1.08 & 1.18 \\
\hline & & & & & & & & & & & & & Ave. & 1.010 & 0.971 & 1.204 \\
\hline & & & & & & & & & & & & & St. dev. & 0.095 & 0.259 & 0.122 \\
\hline
\end{tabular}


Table 8 Kircshner and Collins (1986) columns verification.

\begin{tabular}{|c|c|c|c|c|c|c|c|c|c|c|c|c|c|c|}
\hline \multicolumn{10}{|c|}{ Properties \& geometry } & \multirow{2}{*}{$\begin{array}{c}\text { Comp. } \\
\text { Shear } \\
(\mathrm{kN})\end{array}$} & \multirow{2}{*}{$\begin{array}{l}\text { Exp. } \\
\text { Shear } \\
(\mathrm{kN})\end{array}$} & \multirow{2}{*}{$\begin{array}{l}\text { Vexp./ } \\
\text { Vcomp. }\end{array}$} & \multirow{2}{*}{$\begin{array}{c}\text { Vexp./ } \\
\mathrm{V}_{\mathrm{ACI}}\end{array}$} & \multirow{2}{*}{$\begin{array}{l}\text { Vexp. } \\
V_{\text {MCFT }}\end{array}$} \\
\hline Specimen & $\begin{array}{c}h \\
(\mathrm{~mm})\end{array}$ & $\begin{array}{c}b \\
(\mathrm{~mm})\end{array}$ & $\begin{array}{c}d \\
(\mathrm{~mm})\end{array}$ & $\begin{array}{c}f_{c}^{\prime} \\
(\mathrm{MPa})\end{array}$ & $\begin{array}{c}\rho_{x} \\
(\%)\end{array}$ & $\begin{array}{c}\rho_{y} \\
(\%)\end{array}$ & $\begin{array}{c}f_{y y} \\
\text { (MPa) }\end{array}$ & $\begin{array}{c}f_{u y} \\
\text { (MPa) }\end{array}$ & $N / V$ & & & & & \\
\hline $\mathrm{PC} 1$ & 375 & 489 & 345 & 62.2 & 2.62 & 0.153 & 520 & 684 & 0 & 429 & 437 & 1.02 & 1.22 & 1.07 \\
\hline $\mathrm{PC} 2$ & 375 & 489 & 345 & 62.2 & 2.62 & 0.153 & 520 & 684 & 4 & 844 & 863 & 1.02 & 0.69 & 1.38 \\
\hline $\mathrm{PC} 3$ & 375 & 375 & 345 & 62.8 & 2.62 & 0.131 & 520 & 684 & 4 & 696 & 845 & 1.21 & 0.73 & 1.68 \\
\hline PC4 & 365 & 375 & 335 & 83.1 & 2.63 & 0.142 & 509 & 785 & 0 & 342 & 401 & 1.17 & 1.47 & 1.26 \\
\hline PC5 & 365 & 375 & 335 & 86.9 & 2.63 & 0.142 & 509 & 785 & 8 & 749 & 679 & 0.91 & 0.79 & 0.91 \\
\hline PC6 & 365 & 375 & 335 & 86.9 & 2.63 & 0.142 & 509 & 785 & 4 & 749 & 668 & 0.89 & 0.61 & 1.37 \\
\hline PC7 & 365 & 375 & 335 & 39.9 & 2.63 & 0.142 & 509 & 785 & 0 & 436 & 387 & 0.89 & 1.66 & 1.44 \\
\hline PC8 & 365 & 375 & 335 & 42.4 & 2.63 & 0.142 & 509 & 785 & 4 & 471 & 497 & 1.05 & 0.65 & 1.24 \\
\hline PC9 & 365 & 375 & 335 & 42.9 & 2.63 & 0.142 & 509 & 785 & 8 & 474 & 516 & 1.09 & 0.95 & 1.07 \\
\hline PC10 & 365 & 625 & 335 & 42.9 & 2.63 & 0.142 & 509 & 785 & 4 & 946 & 726 & 0.77 & 0.58 & 1.08 \\
\hline PC11 & 365 & 625 & 335 & 44.7 & 2.63 & 0.142 & 509 & 785 & 8 & 946 & 754 & 0.80 & 0.84 & 0.92 \\
\hline $\mathrm{PC} 12$ & 365 & 375 & 335 & 60 & 2.63 & 0.142 & 509 & 785 & 0 & 389 & 490 & 1.26 & 1.87 & 1.66 \\
\hline PC13 & 365 & 375 & 335 & 60 & 2.63 & 0.142 & 509 & 785 & 4 & 642 & 680 & 1.06 & 0.72 & 1.52 \\
\hline PC14 & 365 & 375 & 335 & 64.5 & 2.63 & 0.142 & 509 & 785 & 8 & 660 & 686 & 1.04 & 0.98 & 1.13 \\
\hline PC15 & 365 & 375 & 335 & 56.6 & 2.63 & 0.142 & 509 & 785 & 20 & 362 & 358 & 0.99 & 1.02 & 1.02 \\
\hline PC16 & 365 & 365 & 335 & 56.6 & 2.63 & 0.667 & 435 & 630 & 4 & 1112 & 945 & 0.85 & 1.05 & 1.05 \\
\hline PC17 & 365 & 365 & 335 & 56.6 & 2.63 & 0.667 & 435 & 630 & 8 & 1112 & 707 & 0.64 & 1.07 & 1.07 \\
\hline PC18 & 365 & 625 & 335 & 29.5 & 2.63 & 0.085 & 509 & 785 & 4 & 655 & 832 & 1.27 & 0.93 & 1.72 \\
\hline PC19 & 365 & 625 & 335 & 29.5 & 2.63 & 0.085 & 509 & 785 & 8 & 655 & 751 & 1.15 & 1.1 & 1.32 \\
\hline $\mathrm{PC} 20$ & 365 & 625 & 335 & 47.3 & 2.63 & 0 & & & 6 & 534 & 715 & 1.34 & 0.64 & 1.19 \\
\hline PC21 & 365 & 625 & 335 & 47.3 & 2.63 & 0 & & & 4 & 534 & 767 & 1.44 & 0.69 & 1.52 \\
\hline $\mathrm{PC} 22$ & 365 & 375 & 335 & 53.2 & 2.63 & 0.142 & 509 & 785 & 0 & 361 & 443 & 1.23 & 1.75 & 1.55 \\
\hline PC23 & 365 & 375 & 335 & 53.2 & 2.63 & 0.142 & 509 & 785 & 3 & 613 & 603 & 0.98 & 0.8 & 1.63 \\
\hline PC24 & 365 & 375 & 335 & 53.2 & 2.63 & 0.142 & 509 & 785 & 1.5 & 526 & 528 & 1.00 & 1.92 & 1.67 \\
\hline & & & & & & & & & & & Ave. & 1.04 & 1.03 & 1.31 \\
\hline & & & & & & & & & & & Std. Dev. & 0.18 & 0.40 & 0.25 \\
\hline
\end{tabular}

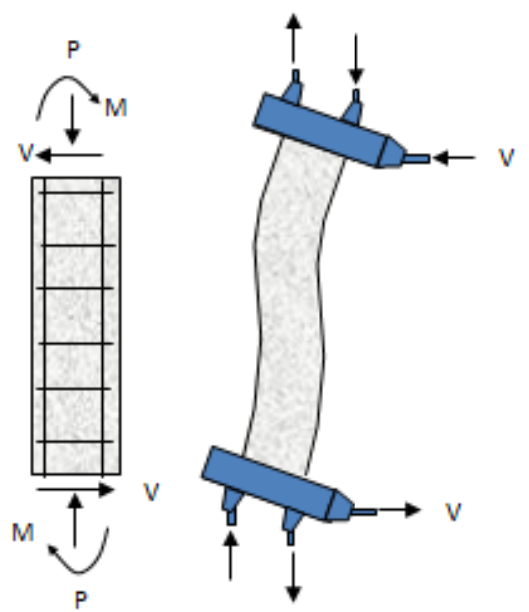

Fig. 16 Application of loads and measurement of deformation.

Here, the experiments (Shioya et al. 1989) are used to investigate more the ability of the proposed method to predict the shear strength of large RC members with different depths or maximum aggregate size. As it is shown in Fig. 17 the shear strength predicted by the proposed formula is in good agreement with the experimental results, which shows the accuracy of the method of considering the size effect. Also the calculation procedure is shown in Table 9.

\section{Conclusions}

Despite extensive research on the behavior of reinforced concrete in shear, there is still considerable disagreement among researchers in proposing and using a rational way of calculating the shear strength of reinforced concrete. Most of the design codes have adopted semiempirical methods with several different expressions for calculating the shear strength under different loading conditions and different types of members. Thus, the shear strength predicted by different current design codes for a particular RC member can vary by factors of more than 2 .

In this paper, on the basis of complex computation of local stresses in the crack surface of RC elements a rational simple formula and computation procedure are proposed for shear design and failure assessment of reinforced concrete members. This proposed method is in good agreement with the experimental results and can 
Table 9 Shioya et al. (1989) beams shear capacity calculation.

\begin{tabular}{|c|c|c|c|c|c|c|c|c|c|c|c|c|c|c|c|c|c|}
\hline \multicolumn{10}{|c|}{ Properties \& geometry } & \multirow[b]{2}{*}{$\begin{array}{c}S_{x} \\
(\mathrm{~mm})\end{array}$} & \multirow[b]{2}{*}{$\begin{array}{c}S_{y} \\
(\mathrm{~mm})\end{array}$} & \multirow[b]{2}{*}{$\begin{array}{c}\theta \\
(\mathrm{mm})\end{array}$} & \multirow[b]{2}{*}{$\begin{array}{c}S_{\theta} \\
(\mathrm{mm})\end{array}$} & \multirow[b]{2}{*}{$\begin{array}{c}\varepsilon_{x} \\
(\mathrm{~mm})\end{array}$} & \multirow[b]{2}{*}{$\begin{array}{c}S_{c} \\
(\mathrm{~mm})\end{array}$} & \multirow[b]{2}{*}{$\begin{array}{c}V_{c} \\
(\mathrm{MPa})\end{array}$} & \multirow[b]{2}{*}{\begin{tabular}{|c|} 
Comp. \\
shear
\end{tabular}} \\
\hline Spec. & $\begin{array}{c}h \\
(\mathrm{~mm})\end{array}$ & $\begin{array}{c}b \\
(\mathrm{~mm})\end{array}$ & $\begin{array}{c}d \\
(\mathrm{~mm})\end{array}$ & $\begin{array}{c}f^{\prime} c \\
(\mathrm{MPa})\end{array}$ & $\begin{array}{c}f_{t} \\
(\mathrm{MPa})\end{array}$ & $\begin{array}{c}\rho_{x} \\
(\%)\end{array}$ & $\begin{array}{c}\rho_{y} \\
(\%)\end{array}$ & $\begin{array}{c}f_{y y} \\
(\mathrm{MPa})\end{array}$ & $\mathrm{N} / \mathrm{V}$ & & & & & & & & \\
\hline 3 & 655 & 300 & 600 & 21.1 & 1.81 & 0.4 & 0 & 440 & 0 & 480 & 655 & 45 & 391.7 & 0.00152 & 0.596 & 0.418 & 75 \\
\hline 5 & 1200 & 500 & 1000 & 21.9 & 2.23 & 0.4 & 0 & 370 & 0 & 800 & 1200 & 45 & 678.8 & 0.00092 & 0.624 & 0.408 & 204 \\
\hline 6 & 2100 & 1000 & 2000 & 28.5 & 2.73 & 0.4 & 0 & 370 & 0 & 1600 & 2100 & 45 & 1284.2 & 0.00162 & 2.080 & 0.350 & 700 \\
\hline 7 & 3140 & 1500 & 3000 & 24.3 & 2.19 & 0.4 & 0 & 360 & 0 & 2400 & 3140 & 45 & 1923.6 & 0.00123 & 2.366 & 0.290 & 1305 \\
\hline
\end{tabular}

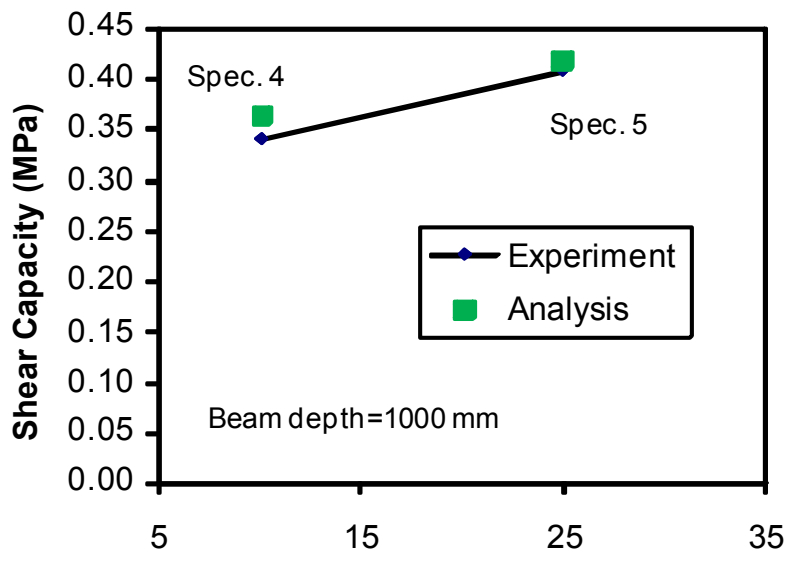

Agg. Size (mm)

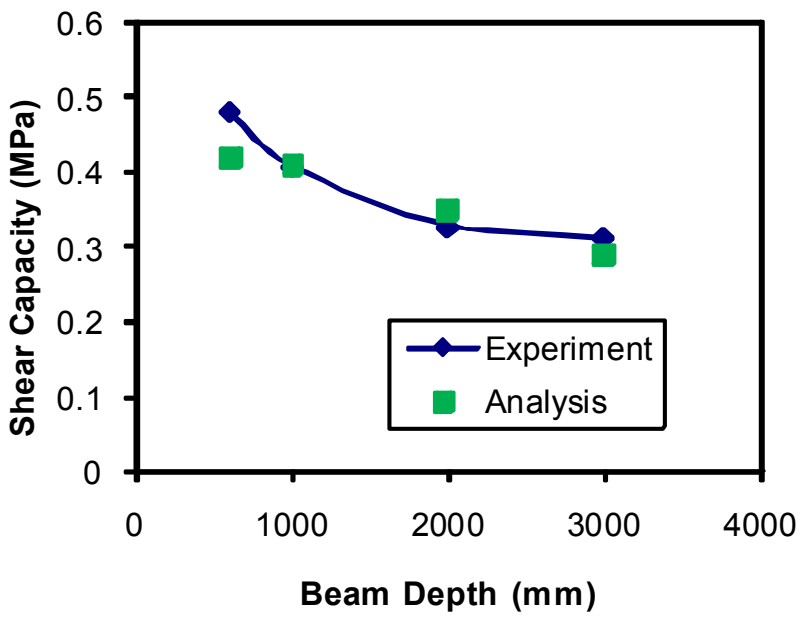

Fig. 17 Size effect verification, tests by Shioya et al. (1989).

be used for different conditions of material properties and loading condition with only one equation. It is shown that the proposed relations can predict the strength of RC members when having high strength concrete, welded wire mesh, different bar distribution and size effect with a good accuracy.

\section{References}

AASHTO-LRFD (1998). "Bridge design specifications and commentary." 2nd Edition, American Association of State Highway and Transportation Officials, Washington D.C.

ACI Committee 318 (2005). "Building code requirements for reinforced concrete (ACI 318-05) and Commentary (318R-05)." American Concrete Institute, Farmington Hills, Mich.

An, X. (1996). "Failure analysis and evaluation of seismic performance for reinforced concrete in shear." Thesis (PhD). Department of Civil Engineering, University of Tokyo.

Bazant, Z. P. and Kim, J. K. (1984). "Size effect in shear failure of longitudinally reinforced beams." $A C I$ Journal, 81(5), 456-468.

Bentz, E. C., Vecchio, F. J., Collins, M. P. (2006). "Simplified modified compression field theory for calculating shear strength of reinforced concrete elements." ACI Structural Journal, 103(4), 614-624.

Bujadham, B., Maekawa, K. (1992). "The universal model for stress transfer across cracks in concrete." Proc of JSCE, 17(451), 277-287.

Collins, M. P. (1978). "Towards a rational theory for RC members in shear." Journal of Structural Division, ASCE, 104(4), 649-666.

Collins, M. P. and Kuchma, D. (1999). "How safe are our large, lightly reinforced concrete beams, slabs, and footings?" ACI Structural Journal, 96(4), 482490.

Collins, M. P. and Mitchell, D. (1991). "Prestressed concrete structures." New Jersey: Prentice Hall.

Collins, M. P., Mitchell, D. Adebar, P., Vecchio, F. J. (1996). "A general shear design method." $A C I$ Structural Journal, 93(1), 36-45.

CSA Committee A23.3 (1984). "Design of concrete structures for buildings (CSA A23.3)." Canadian Standards Association, Etobicoke, Ont.

Kani, G. N. J. (1967). "How safe are our large reinforced concrete beams?" ACI Journal, 64(3), 128141.

Kennedy, R. P. (1967). "A statistical analysis of the shear strength of reinforced concrete beams." Thesis (PhD). Stanford University.

Kirschner, U. and Collins, M. P. (1986). "Investigating the behavior of reinforced concrete shell elements." Department of Civil engineering, University of Toronto, Publication No. 86-09.

Li, B., Maekawa, K. and Okamura, H. (1989). "Contact 
density model for stress transfer across cracks in concrete." Journal of the Faculty of Engineering, University of Tokyo, 40(1), 9-52.

Maekawa, K., Pimanmas. A. and Okamura. H. (2003). "Nonlinear mechanics of reinforced concrete." SPON Press, London.

Mitchell, D. and Collins, M. P. (1974). "Diagonal compression field theory- a rational model for structural concrete in pure torsion." ACI Journal, 71, 396-408.

Okamura, H. and Hiagai, T. (1980). "Proposed design equation for shear strength of reinforced concrete beams without web reinforcement." Proc., Japan Society of Civil Engineering, 300, 131-141.

Okamura, H. and Maekawa K. (1991). "Nonlinear analysis and constitutive models of reinforced concrete." Tokyo, Japan: Gihodo-Shuppan.

Pang, X. B. and Hsu, T. (1995). "Behavior of reinforced concrete membrane elements in shear." $A C I$ Structural Journal, 92(6), 665-679.

Priestley, M. J. N, Seible, F. Chai, Y. H. (1992). "Design guidelines for assessment retrofit and repair of bridges for seismic performance." Structural systems research project, University of California, Report No. SSRP 92/01.

Rahal, K. N. and Collins, M. P. (1999). "Background to the general method of shear design in the 1994 CSAA23.3 standard." Canadian Journal of Civil Engineering, 26, 827-839.

Salem, H. (1998). "Enhanced tension stiffening model and application to nonlinear dynamic analysis or reinforced concrete." Thesis ( $\mathrm{PhD})$. Department of Civil Engineering, University of Tokyo.

Shima, H., Chou, L. and Okamura, H. (1987). "Micro and macro models for bond in reinforced concrete." Journal of faculty of engineering, University of Tokyo (B), 39(2), 133-194.

Shioya, T., Iguro, M., Nojiri, Y., Akiayma, H. and Okada, T. (1989). "Shear strength of large reinforced concrete beams. Fracture mechanics: application to concrete." SP-118, ACI, Detroit, 259-279.

Soltani, M., An, X. and Maekawa, K. (2003).
"Computational model for post cracking analysis of RC membrane elements on local stress-strain characteristics." Engineering Structures, 25, 9931007.

Soltani, M., An, X. and Maekawa, K. (2004). "Cracking response and local stress characteristics of RC membrane elements reinforced with welded wire mesh." Cement \& Concrete Composites 26(26), 389404.

Soltani, M., An, X. and Maekawa, K. (2005). "Localized nonlinearity and size-dependent mechanics of in-plane RC element in shear." Engineering Structures, 27, 891-908.

Taylor, H. P. J. (1972). "Shear Strength of Large Beams." Journal of Structural Division, Proc. of ASCE, 2473-2490.

Vecchio, F. J. and Chan, C. C. L. (1990). "Reinforced concrete membrane elements with perforations." ASCE Journal of Structural Engineering, 116(3), 7278.

Vecchio, F. J. and Collins, M. P. (1982). "The response of reinforced concrete to in-plane shear and normal stresses." Department of Civil engineering, University of Toronto, Publication No. 82-03.

Vecchio, F. J. and Collins, M. P. (1986). "The modified compression field theory for reinforced concrete elements subjected to shear." ACI Journal, 83(2), 219-31.

Vecchio, F. J., Collins, M. P. and Aspiotis, J. (1994). "High strength concrete elements subjected to shear." ACI Structural Journal, 91(4), 423-433.

Walraven, J. C. (1981). "Fundamental analysis of aggregate interlock." ASCE Journal of Structural Division, 107(ST11), 2245-2270.

Walraven, J. C. and Lehwalter, N. (1994). "Size effects in short beams loaded in shear." ACI Structural Journal, 91(5), 585-593.

Zhang, L. X. and Hsu, T. T. C. (1998). "Behavior and analysis of $100 \mathrm{MPa}$ concrete membrane elements." Journal of Structural Engineering, ASCE, 124(1), 7278. 